\title{
Spillover Transmission Is Mediated by the Excitatory GABA Receptor LGC-35 in C. elegans
}

\author{
Meghan A. Jobson, ${ }^{3,4 \star}$ Chris M. Valdez, ${ }^{1,2 \star}$ Jann Gardner, ${ }^{4}$ L. Rene Garcia, ${ }^{5,7}$ Erik M. Jorgensen, ${ }^{3,4,6}$ and Asim A. Beg ${ }^{1,2}$ \\ ${ }^{1}$ Department of Pharmacology, University of Michigan, Ann Arbor, Michigan 48109, ${ }^{2}$ Neuroscience Program, University of Michigan, Ann Arbor, Michigan \\ 48109, ${ }^{3}$ Program in Neuroscience, University of Utah School of Medicine, Salt Lake City, Utah 84132, ${ }^{4}$ Department of Biology, University of Utah, Salt Lake \\ City, Utah 84132, ${ }^{5}$ Department of Biology, Texas A\&M University, College Station, Texas 77843, ${ }^{6}$ Howard Hughes Medical Institute, University of Utah, Salt \\ Lake City, Utah 84132, and ${ }^{7}$ Howard Hughes Medical Institute, Texas A\&M University, College Station, Texas 77843
}

Under most circumstances, GABA activates chloride-selective channels and thereby inhibits neuronal activity. Here, we identify a GABA receptor in the nematode Caenorhabditis elegans that conducts cations and is therefore excitatory. Expression in Xenopus oocytes demonstrates that LGC-35 is a homopentameric cation-selective receptor of the cys-loop family exclusively activated by GABA. Phylogenetic analysis suggests that LGC-35 evolved from GABA-A receptors, but the pore-forming domain contains novel molecular determinants that confer cation selectivity. LGC-35 is expressed in muscles and directly mediates sphincter muscle contraction in the defecation cycle in hermaphrodites, and spicule eversion during mating in the male. In the locomotory circuit, GABA release directly activates chloride channels on the muscle to cause muscle relaxation. However, GABA spillover at these synapses activates LGC-35 on acetylcholine motor neurons, which in turn cause muscles to contract, presumably to drive wave propagation along the body. These studies demonstrate that both direct and indirect excitatory GABA signaling plays important roles in regulating neuronal circuit function and behavior in C. elegans.

Key words: C. elegans; cys-loop; GABA; ion selectivity

\section{Introduction}

The family of cysteine-loop ligand-gated ion channels (cys-loop LGICs) mediate rapid neurotransmission and consists of four major receptor types: acetylcholine, serotonin, glycine, and GABA receptors. These receptors are comprised of five subunits arranged to form a central ion-conducting pore (Thompson et al., 2010). Each subunit is composed of an extracellular ligandbinding domain (LBD), a cysteine-loop motif ( $\left.\mathrm{C}-\mathrm{X}_{13}-\mathrm{C}\right)$, four transmembrane domains (M1-M4), and a large intracellular loop

\section{Received 0ct. 30, 2014; revised Dec. 10, 2014; accepted Dec. 23, 2014}

Author contributions: M.A.J., C.M.V., J.G., L.R.G., E.M.J., and A.A.B. designed research; M.A.J., C.M.V., J.G., L.R.G., E.M.J., and A.A.B. performed research; L.R.G. and E.M.J. contributed unpublished reagents/analytic tools; M.A.J., C.M.V., J.G., L.R.G., E.M.J., and A.A.B. analyzed data; M.A.J., C.M.V., J.G., L.R.G., E.M.J., and A.A.B. wrote the paper.

This work was supported by the Alfred P. Sloan Foundation, The Hartwell Foundation (to A.A.B), and the National Institutes of Health (to E.M.J.). We thank members of the A.A.B. and E.M.J. laboratories for comments on the manuscript; M. Wayne Davis and Gunther Hollopeter for providing expert technical assistance using the MosDEL technique; Rob Hobson for providing plasmids and reagents; Jonathan Delafield Butt for assisting with high-speed video analysis; Shawn Xu for the Pacr-2::mCherry plasmid; Rob Weymouth for providing Xenopus 0ocytes; Georgina Nicholl for cRNA preparation, 0ocyte injections, and preliminary data; and Patrick Mac for critical reading of the manuscript. Some strains were provided by the Caenorhabditis Genetics Center, which is funded by the National Institutes of Health Office of Research Infrastructure Programs (P40 0D010440). The lgc-35(tm1444) allele was provided by the Japan National BioResource Project, and the transposon insertion strain Igc-35(ttTi13013) was provided by the NemaGENETAG consortium.

The authors declare no competing financial interests.

*M.A.J. and C.M.V. contributed equally to this study.

Correspondence should be addressed to either of the following: Dr. Asim A. Beg, University of Michigan, Department of Pharmacology, 1150 W. Medical Center Drive, 1301D MSRB III, Ann Arbor, MI 48109, E-mail: asimbeg@umich.edu; or Dr. Erik M. Jorgensen, University of Utah, Biology Department, 257 South 1400 East, Room 201, Salt Lake City, UT 84112, E-mail: jorgensen@biology.utah.edu.

DOI:10.1523/JNEUROSCI.4557-14.2015

Copyright $\odot 2015$ the authors $\quad 0270-6474 / 15 / 352803-14 \$ 15.00 / 0$ connecting M3 to M4. Typically, cation conductance mediates excitation and anion conductance mediates inhibition.

The Caenorhabditis elegans (C. elegans) genome encodes $\sim 102$ cys-loop receptor subunits, making it the largest and most diverse known eukaryotic cys-loop superfamily (Jones and Sattelle, 2008). As in vertebrates, there are classical excitatory acetylcholine and inhibitory GABA receptors. However, C. elegans uses an arsenal of unusual cys-loop receptor subtypes, including inhibitory anion-selective receptors gated by acetylcholine, choline, serotonin, dopamine, tyramine, and octopamine; and excitatory cation-selective receptors activated by GABA, betaine, and protons (Bamber et al., 1999; Ranganathan et al., 2000; Yassin et al., 2001; Beg and Jorgensen, 2003; Putrenko et al., 2005; Beg et al., 2008; Jones and Sattelle, 2008; Pirri et al., 2009; Ringstad et al., 2009; Peden et al., 2013). This diversity adds tremendous flexibility, as each transmitter can be excitatory, inhibitory, or have mixed action within the same tissue depending on the dedicated or combinatorial expression of particular receptor subtypes. Importantly, only a fraction of cys-loop receptors have been characterized in C. elegans, suggesting that new modes of neurotransmission within this simple organism have yet to be identified.

Over 20 years ago, a strategy was designed to identify genes required for GABA function in C. elegans (McIntire et al., 1993a). Three major GABA-dependent behavioral phenotypes were identified using genetic and laser ablation techniques: locomotion, foraging, and defecation (McIntire et al., 1993b). During locomotion and foraging, GABA acts to relax body muscles via 
GABA-activated chloride channels and thereby helps generate a sinusoidal wave along the body axis (Bamber et al., 1999). By contrast, GABA stimulates enteric muscle contraction during defecation via the GABA-gated cation channel EXP-1 (McIntire et al., 1993b; Beg and Jorgensen, 2003). The enteric muscles comprise the intestinal, anal depressor, and sphincter muscles. Although EXP-1 is required for intestinal and anal depressor muscle contraction, it is neither expressed in, nor required for, sphincter muscle contraction (Beg and Jorgensen, 2003). Importantly, GABA is the primary neurotransmitter released on the enteric muscles, suggesting that an unidentified GABA receptor mediates sphincter muscle contraction (White et al., 1986).

Here, we demonstrate that $l g c$ - 35 encodes a homopentameric excitatory GABA-gated cation channel that is required for diverse modes of neuromuscular transmission. Our findings demonstrate that LGC-35 mediates sphincter muscle contraction, is expressed in a subset of acetylcholine motor neurons where it functions as a spillover receptor to modulate locomotory behavior, and is involved in male-specific copulatory muscle contraction. Together, our data show that excitatory GABA signaling is not a specialized mode of signaling confined to enteric muscle function but plays a broader role in the modulation of neuronal circuits in C. elegans.

\section{Materials and Methods}

\section{Strains}

For all experiments, the Bristol N2 strain was used as the wild-type control. Worms were grown at $22^{\circ} \mathrm{C}$ on NGM plates seeded with Escherichia coli OP50 or HB101. EG4787 lgc-35(tm1444) II, a deletion mutation removing the first five exons of $\operatorname{lgc}$ - 35 , was obtained from the Japan National BioResource project and outcrossed six times. To obtain a second null allele of $\operatorname{lgc}-35$, the MosDEL technique was used to generate the targeted deletion EG6027 lgc-35(ox469) II (Frøkjær-Jensen et al., 2010). Briefly, the Mos1 transposon in lgc-35(ttTi13013) II was remobilized causing a break in the DNA, which was repaired by a template encompassing a deletion of $\operatorname{lgc}$-35. The following strains were used for experiments described in this work: JT6 exp-1(sa6) II, EG276 exp-1(ox276) II, EG4920 unc-25(e156) III, EG7856 unc-49(e407) III, EG3328 exp1(ox276) II; unc-49(e407) III, and CB1489 him-8(e1489) IV. The following strains were generated for the experiments described in this work: EG4563 lgc-35(tm1444) exp-1(ox276) II, EG4869 lgc-35(tm1444) exp1(ox276) II; unc-49(e407) III, EG5035 lgc-35(tm1444) exp-1(ox276) II; lin-15(n765ts) X, EG5377 lgc-35(tm1444) II; him-8(e1489) IV, EG5330 exp-1(ox276) lgc-35(tm1444) II; oxEx1291 [Plgc-35::LGC-35::GFP, Psur5::GFP, lin-15(+)], EG7253 lgc-35(tm1444) II; oxEx1291[Plgc-35::LGC35::GFP, Psur-5::GFP, lin-15(+)], and EG5331 lgc-35(tm1444) II; unc-49(e407) III; him-8(e1489) IV; oxEx1328 [Plgc-35::LGC35::GFP::let858-UTR, Psur-5::GFP, lin-15(+)].

\section{Sequences}

Orthologs of LGC-35 found in nematode species include: C. japonica (JA09778, 87\% identity), C. brenneri (CN11371, 76\% identity), C. briggsae (CB18417, 71\% identity), and P. pacificus (PP42968, 58\% identity), and in the parasitic nematodes Ascaris suum (ERG83865.1, 43\% identity), Brugia malayi (XP_001900837.1, 48\% identity), Loa loa (XP_003137178.1, 47\% identity), and Onchocera volvulus (OVOC9886, 41\% identity).

\section{Fluorescent protein expression constructs}

Transcriptional fusions. A $7.6 \mathrm{~kb}$ genomic fragment, including $\sim 3 \mathrm{~kb}$ upstream sequence, the $3.54 \mathrm{~kb}$ Y46G5A.26 (lgc-35) open reading frame, and $1.0 \mathrm{~kb}$ downstream sequence was PCR amplified and cloned into the vector pCR2.1 (Invitrogen) to generate pAB12. To generate the transcriptional reporters, a $2.9 \mathrm{~kb} \operatorname{lgc}-35$ promoter fragment was PCR amplified from pAB12 using primers containing attB4 and attB1 sites. The promoter fragment with flanking sites was recombined into pDONR P4$\mathrm{P} 1 \mathrm{R}$ (Invitrogen) using the $\mathrm{BP}$ recombination reaction to make pMJ50. The EGFP transcriptional reporter pMJ52 (Plgc-35::EGFP::let-858 terminator) was made by recombining pMJ50, pGH115, and ADA-126 in a multisite LR reaction into pDEST R4-R3 (Invitrogen). The TagRFP transcriptional reporter pMJ53 (Plgc-35::TagRFP::let-858 terminator) was made by recombining pMJ50, pRH142, ADA-126 in a multisite LR reaction into pDEST R4-R3 (Invitrogen). Sequencing and restriction digests confirmed correct construction of all reporter constructs. The two transcriptional reporters, pMJ52 and pMJ53, were separately injected at $20 \mathrm{ng} / \mu \mathrm{l}$ with $80 \mathrm{ng} / \mu \mathrm{l}$ of pEK1 (lin-15+) into lin-15(n765ts) animals to generate oxEx1314(pMJ52) and oxEx1315( pMJ53).

\section{Translational GFP fusions}

To determine protein localization, GFP was inserted into the open reading frame of LGC-35 within the intracellular loop between M3-M4. To generate $\mathrm{pAB} 10$, an in-frame translational LGC-35::GFP fusion plasmid, an XmaI/AgeI restriction fragment from pPD102.22 containing the EGFP coding region was ligated to AgeI linearized pAB12. Sequencing confirmed that the EGFP insertion site was in-frame within pAB10. pAB10 was injected at $30 \mathrm{ng} / \mu \mathrm{l}$ with pEK1 $($ lin-15+) at $30 \mathrm{ng} / \mu \mathrm{l}$ and $1 \mathrm{~kb}+$ DNA Ladder at $40 \mathrm{ng} / \mu \mathrm{l}$ into lin-15(n765ts) animals to generate oxEx1253. An additional translational reporter was generated using the gateway system. LGC-35::GFP from pAB10 was PCR amplified using primers containing attB1 and attB2 sites. The PCR product was recombined with attP1 and attP2 sites into pDONR P1-P2R (Invitrogen) using the BP recombination reaction to make pMJ51 (LGC-35::GFP). An EGFP translational reporter, pMJ54 (Plgc-35::LGC-35::GFP-let-858 terminator), was made by recombining pMJ50, pMJ51, ADA-126 in a multisite LR reaction into pDEST R4-R3 (Invitrogen).

\section{Cell identification}

To determine whether LGC-35 protein is expressed in acetylcholine motor neurons (VA,VB, DA, DB), an injection mix of $30 \mathrm{ng} / \mu \mathrm{l}$ of $\mathrm{pAB} 10,2.5$ $\mathrm{ng} / \mu \mathrm{l}$ of pCFJ90, $30 \mathrm{ng} / \mu \mathrm{l}$ of Pacr-2::mCherry, and $37.5 \mathrm{ng} / \mu \mathrm{l}$ of $1 \mathrm{~Kb}+$ DNA Ladder (Invitrogen) was injected into wild-type animals to generate $a a b E x 13$. To determine whether LGC-35 is expressed in GABA motor neurons (DD and VD), $30 \mathrm{ng} / \mu \mathrm{l}$ of $\mathrm{pAB} 10,30 \mathrm{ng} / \mu \mathrm{l}$ of $\mathrm{pGH} 21$, and 40 $\mathrm{ng} / \mu \mathrm{l}$ of $\mathrm{pEK} 1($ lin-15+) were injected into lin-15(n765ts) animals to generate oxEx1224. Cell identifications were made from young adult hermaphrodite animals using the vulva as a landmark for orientation. Sequencing and restriction digests confirmed correct construction for all constructs. Standard microinjection techniques were used to generate all transgenic strains (Mello et al., 1991). Strains were imaged on a Pascal LSM5 confocal microscope (Carl Zeiss) or Nikon A1R confocal.

\section{lgc-35 rescue constructs}

Rescue of $l g c-35(t m 1444)$ mutants was achieved by injecting $15 \mathrm{ng} / \mu \mathrm{l}$ of pMJ54, $5 \mathrm{ng} / \mu \mathrm{l}$ of Psur-5::GFP, and $80 \mathrm{ng} / \mu \mathrm{l}$ of pEK1 generating the array $0 x \operatorname{Ex} 1291$.

\section{RNA interference (RNAi)}

RNAi was performed by feeding (Kamath et al., 2003). Ten adult gravid hermaphrodites were placed on RNAi bacteria and allowed to lay eggs for $6 \mathrm{~h}$ before being removed. RNAi plates were grown at room temperature until eggs grew into adults $(2-3 \mathrm{~d})$. Ten F1 young adult animals were scored for defecation cycle steps from each genotype as previously described (Thomas, 1990).

\section{Behavioral assays}

Defecation. To determine enteric muscle contractions (Emc) per defecation cycle, animals were scored for a positive enteric muscle contraction following a posterior body contraction (Emc/Pboc). Each animal was observed for 11 cycles, and 15 animals were scored for each genotype. Animals were raised and scored at room temperature $\left(22^{\circ} \mathrm{C}\right)$ on OP50 bacteria.

\section{High-speed video}

Contraction of the intestinal muscles occurs on a millisecond time scale. To observe contraction of the intestinal muscle, videos were recorded at 60 frames per second at $400 \times$ total magnification. The raw data were converted to an AVI file and slowed to 5 frames a second to manage the large size of these files. The videos were edited to capture the expulsion step for qualitative analysis. 


\section{Worm tracking}

Worm movement was analyzed by filming $\operatorname{lgc}$-35(tm1444), or $\operatorname{lgc}$ 35(tm1444) oxEx1291, or wild-type (N2) animals. Each genotype was raised and filmed at room temperature $\left(22^{\circ} \mathrm{C}\right)$ on OP50 bacteria on standard NGM plates. Young adult worms were picked individually and placed briefly on an intermediate NGM plate until clear of residual bacteria. An individual animal was then placed on a test plate of room temperature NGM agar and allowed to move for $1 \mathrm{~min}$ before filming. Each animal was filmed for a single $30 \mathrm{~s}$ duration. Worm movement was filmed using a Leica MS 5 microscope, a Prior Scientific OptiScan II moving stage, and a CCD Firewire camera (Sony XCD-V60). Worm locomotion was analyzed using the Track-A-Worm software platform (Wang and Wang, 2013).

\section{Aldicarb}

We determined sensitivity to aldicarb, an acetylcholine esterase inhibitor, by measuring the onset of paralysis after exposure to $1 \mathrm{~mm}$ aldicarb as previously described (Mahoney et al., 2006). Thirty worms were placed on an NGM plate treated with aldicarb and screened for paralysis. Conditions were repeated in triplicate.

\section{Thrash assay}

Locomotor defects were quantified by counting the number of body thrashes in $100 \mu$ l of liquid M9 media at room temperature for a 2 min interval (Miller et al., 1996). Single animals were placed into an agarose coated well of a 96-well plate and allowed to acclimate for 2 min before recording. Animals were recorded using a Leica IC80HD camera for 2 min. The total number of body bends was counted offline by slowing videos to one-fourth speed using ImageJ. A blinded scorer counted the total number of body bends and divided this number by 2 to yield a body bend/minute count.

\section{Spicule eversion and rescue}

To determine whether spicule eversion and retraction were functional, males were scored for functional spicules (spicules that could retract into the body after attempting to mate over time). Spicules that were permanently everted and were unable to retract into the body were scored as nonfunctional. Ten young adult males and hermaphrodites were fed on an OP50 plate for $24 \mathrm{~h}$. At $24 \mathrm{~h}$, a new group of 10 virgin hermaphrodites were introduced and the older hermaphrodites were removed to increase mating attempts. At $48 \mathrm{~h}$, the males' spicules were scored for functionality. him-8(e1489) was the control strain, and all genotypes were in a him-8(e1489) background to maintain males in the population.

Rescue of $\operatorname{lgc}$-35(tm14444) II; unc-49(e407) III; him-8(e1489) IV mutants was achieved by injecting $15 \mathrm{ng} / \mu \mathrm{l}$ of pMJ54, $5 \mathrm{ng} / \mu \mathrm{l}$ of pTG96, and $80 \mathrm{ng} / \mu \mathrm{l} \mathrm{EK1}($ lin-15+) into triple mutant animals generating the array oxEx1328.

\section{Male mating}

Male mating efficiency was assessed as previously described (Hodgkin, 1983). One young adult male was placed on an NGM plate seeded with HB101 with four young adult wild-type hermaphrodites. Males were removed at different time intervals (1, 3, 6, and $24 \mathrm{~h}$ ). At day 3 and 4, plates were blinded for genotype and were scored by eye for cross progeny. All male genotypes tested were in a him-8(e1489) background.

To determine whether males could sire progeny over time $120 \mathrm{~L} 4$ lgc-35(tm1444) II; him-8(e1489) IV males and 120 L4 him-5(e1490) males were separated into populations of 20 worms per plate. Each day for $6 \mathrm{~d}, 20$ adult males were tested for mating potency. Mating potency was measured by pairing a single male with a single 24 -h old virgin adult pha-1(ts) hermaphrodite on a plate containing a $10 \mathrm{~mm}$ OP50 lawn. Mating plates were incubated at $20^{\circ} \mathrm{C}$ and scored after $3 \mathrm{~d}$ for the presence of at least one cross progeny.

\section{Electrophysiology}

LGC-35 cDNA isolation. To determine the full-length mRNA of $l g c-35$, wild-type poly-A + selected RNA was subjected to RT-PCR. The 5' end of the gene was determined using circular RACE (Maruyama et al., 1995), and the $3^{\prime}$ end of the gene was predicted by sequence analysis of the genome based on predictions that had homology to the fourth trans- membrane domain of EXP-1. Full-length cDNAs were isolated by designing oligonucleotide primers to the $5^{\prime}$ and $3^{\prime}$ untranslated regions of Y46G5A.26. PCR products were cloned into the pCR2.1 TA cloning vector (Invitrogen), and cDNAs were sequenced to obtain full-length errorfree clones (Applied Biosystems).

Xenopus oocyte expression. A SpeI/XhoI fragment containing the fulllength $l g c-35 \mathrm{cDNA}$, including the $5^{\prime}$ and $3^{\prime}$ UTRs, was cloned into the SpeI/XhoI sites of pSGEM (courtesy of M. Hollmann), creating plasmid pAB08. Capped RNA was prepared using the T7 mMessage mMachine kit (Ambion). Xenopus oocytes were collected and injected with $10 \mathrm{ng}$ of cRNA, and two-electrode voltage-clamp recordings were performed 2-5 $\mathrm{d}$ after injection.

Dose-response and ion selectivity experiments. The standard bath solution for dose-response and control I-V experiments was Ringer's (in mm): $115 \mathrm{NaCl}, 2.5 \mathrm{KCl}, 1.8 \mathrm{CaCl}_{2}, 10 \mathrm{HEPES}, \mathrm{pH} 7.2, \mathrm{NaOH}$. For dose-response experiments, each oocyte was subjected to a $5 \mathrm{~s}$ application of GABA (1-1000 $\mu \mathrm{M})$ with $2 \mathrm{~min}$ of wash between applications. Ion selectivity experiments and data analysis were performed as previously described (Beg and Jorgensen, 2003). All recording were done at room temperature. We used $3 \mathrm{M} \mathrm{KCl}$-filled electrodes with a resistance between 1 and $3 \mathrm{M} \Omega$. A $3 \mathrm{M} \mathrm{KCl}$ agar bridge was used to minimize liquid junction potentials, and all liquid junction potentials arising at the tip of the recording electrode were corrected online.

\section{Statistical analysis}

Statistical analyses were performed using GraphPad Prism 6. Two-tailed unpaired Student's $t$ tests were performed to determine the difference between two genotypes ( $p<0.05$ was considered significant). One-way ANOVA with Tukey post hoc test was used for comparison involving more than two groups. Data are reported as mean \pm SEM unless otherwise noted, and all experiments were performed blind to the observer.

\section{Results}

\section{LGC-35 is a GABA-gated cation-selective receptor}

We identified $\lg c$-35 (ligand-gated channel-35) by searching the C. elegans genome for exp-1 homologs. LGC-35 is most closely related to the excitatory GABA receptor EXP-1 (53\% identity) and contains the canonical motif $\left(\mathrm{C}-\mathrm{X}_{13}-\mathrm{C}\right)$ that defines the cysloop superfamily (Fig. 1A,B). LGC-35 contains highly conserved amino acid residues within the putative GABA binding pocket and transmembrane domains (Fig. $1 C$; data not shown). The LGC-35 M2 domain region, which lines the ion channel pore and determines ion selectivity is nearly identical to the cationselective EXP-1 receptor (Fig. 1D). The pore domain seems to have arisen by deletion of the proline, alanine, and arginine residues (PAR motif) that are critical for chloride ion selectivity in ionotropic GABA receptors but does not otherwise resemble the cation-permeable pore found in acetylcholine and serotoningated ion channels (Fig. 1D) (Keramidas et al., 2000; Beg and Jorgensen, 2003). This unusual channel family is confined to nematodes; homologs of LGC-35 and EXP-1 are not readily identified in other phyla (see Materials and Methods).

To determine whether LGC-35 can form a functional GABA receptor, we expressed complementary RNA (cRNA) in Xenopus laevis oocytes and tested for receptor activity using two-electrode voltage-clamp recordings. Application of a panel of ligands revealed that LGC-35-expressing oocytes evoked whole-cell currents in response to GABA, but not other ligands; water-injected oocytes did not respond to GABA (Fig. 2A; data not shown). LGC-35 was activated in a dose-dependent manner by GABA, with a median effective concentration $\left(\mathrm{EC}_{50}\right)$ of $\sim 15 \mu \mathrm{M}$ (Fig. $2 B, C)$.

To determine LGC-35 ion selectivity, we substituted extracellular ions and measured the reversal potentials of agonist-evoked responses. In control solution, the GABA-dependent current reversed at $-11 \mathrm{mV}$, similar to the nonselective cation channel, 
A

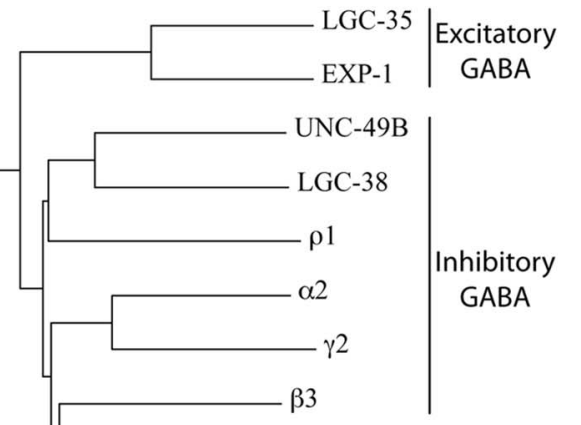

GlyR $\alpha 1$ Glycine

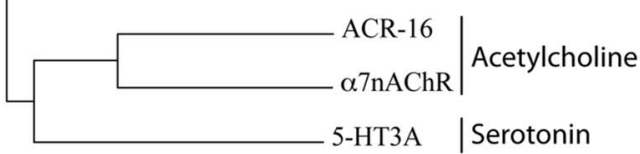

B

LGC-35

EXP-1

nAChR $\alpha 7$

5-HT3AR

GABA-A $\alpha_{1}$

GABA-A $\beta_{3}$

GABA-A $\gamma_{2}$

GlyR $\alpha_{1}$

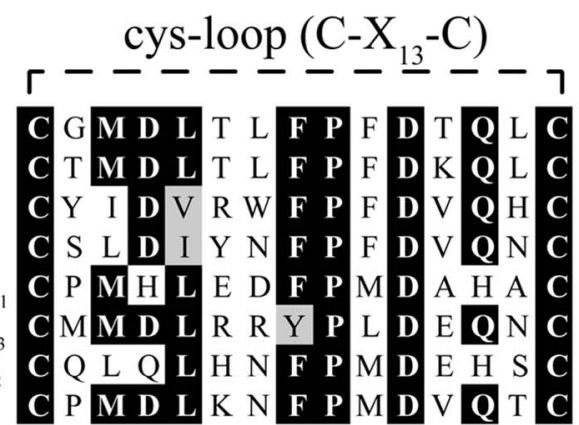

C

Ligand Binding Loops

\begin{tabular}{|c|c|c|c|c|c|}
\hline & $\Delta$ & B & $C$ & & \\
\hline & P D T F V & S Y G & T GDY $\mathrm{S} R \mathrm{~L}$ Y & F Y R E S W & $\mathbf{L} \mathbf{Y} S \mathrm{R} \mathbf{R} \mathbf{L}$ \\
\hline$\langle\mathrm{P}$ & P D T F $\mathbf{F}$ P & S Y G Y T & $\mathbf{T} \mathbf{G} N \mathbf{Y} \quad S \quad R \quad L \quad Y$ & F Y $\mathbf{R}$ E $\mathrm{S}$ W & L Y $S$ R R I $\mathrm{S}$ \\
\hline $\operatorname{ChR} \alpha 7$ & $\begin{array}{l}P \text { D I L L Y } \\
\mathbf{N}\end{array}$ & S W S Y G & K E P Y P D V T & W L Q M S W & QY $\mathrm{L} P \mathrm{P}_{\mathrm{C}} \mathrm{I}$ \\
\hline HT3AR & P D I L I NE & $\mathbf{S}$ W L H T & $\mathrm{S} N \mathrm{Y} Y \mathrm{~A}$ E M K & W Y R Q Y W & Q N Y K P L Q \\
\hline $\mathrm{ABA}-\mathrm{A} \alpha_{1}$ & P D T F F H $\mathbf{N}$ & S $\mathbf{Y} A \mathbf{Y} \mathbf{T}$ & T GE Y V V M T & $\mathbf{F} F \mathbf{R} \mathbf{Q} \mathrm{S} \mathbf{W}$ & $\mathbf{L} \mathbf{Y} \mathrm{T} M \mathbf{R} \mathbf{L} \mathbf{T}$ \\
\hline $\mathrm{BA}-\mathrm{A} \beta_{3}$ & P D T Y F L N & S Y G Y T & 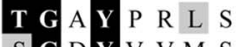 & $\bar{Y} F Q Q Y w$ & $\begin{array}{lllllll}\mathbf{L} & \mathbf{Y} & \mathrm{G} & \mathrm{L} & \mathbf{R} & \mathbf{I} & \mathbf{T} \\
\end{array}$ \\
\hline $\begin{array}{l}\text { ABA-A } \gamma_{2} \\
\text { yR } \alpha\end{array}$ & \begin{tabular}{llllll|l} 
P & $\mathbf{D}$ & $\mathbf{T}$ & $\mathbf{F}$ & $\mathbf{F}$ & $\mathrm{R}$ & $\mathbf{N}$ \\
P & $\mathbf{D}$ & $\mathrm{L}$ & $\mathbf{F}$ & $\mathbf{F}$ & $\mathrm{A}$ & $\mathbf{N}$
\end{tabular} & $\begin{array}{lllll}\mathbf{S} & \mathbf{Y} & \mathbf{G} & \mathbf{Y} & \mathbf{P} \\
\mathbf{S} & \mathbf{F} & \mathbf{G} & \mathbf{Y} & \mathbf{T}\end{array}$ & 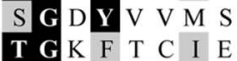 & $\begin{array}{lllllll}\mathbf{F} & \mathrm{F} & \mathrm{A} & \mathbf{Q} & \mathrm{T} & \mathbf{W} \\
\mathbf{F} & \mathrm{L} & \mathbf{R} & \mathbf{O} & \mathrm{O} & \mathbf{W}\end{array}$ & \begin{tabular}{ll|lllll}
$\mathbf{L}$ & $\mathbf{Y}$ & $\mathrm{T}$ & $\mathrm{L}$ & $\mathbf{R}$ & $\mathbf{L}$ & $\mathbf{T}$ \\
$\mathbf{L}$ & $\mathbf{Y}$ & $\mathrm{S}$ & $\mathrm{I}$ & $\mathbf{R}$ & $\mathbf{L}$ & $\mathbf{T}$
\end{tabular} \\
\hline
\end{tabular}

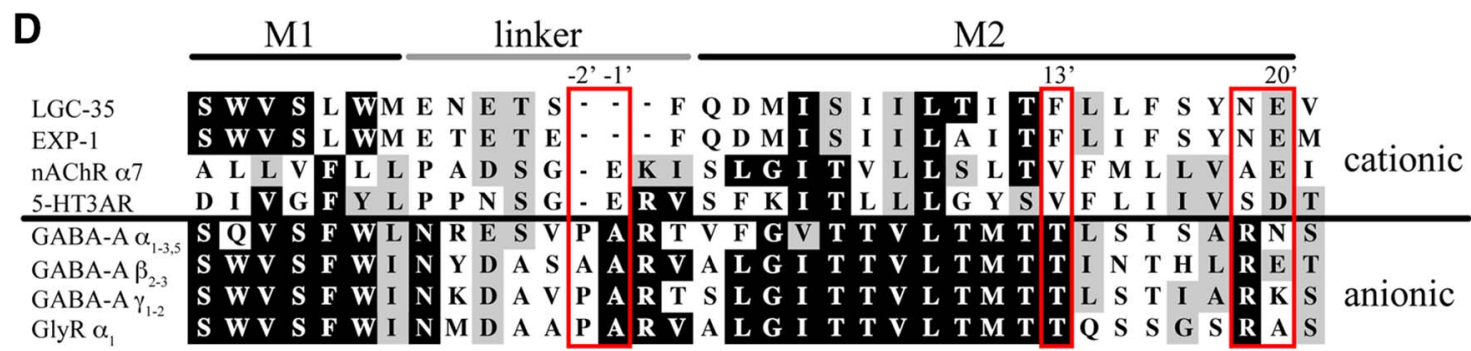

Figure 1. Igc-35 encodes for a cys-loop GABA receptor. A, Phylogenetic tree of human and C. elegans cys-loop LGICs. Alignments were performed using clustalX, and the tree was generated by the "neighbor-joining" bootstrap method. LGC-35 is most closely related to the cation-selective GABA receptor EXP-1. GenBank Accession numbers: C. elegans sequences: UNC-49B (CAC42346.1), ACR-16 (P4818.1), LGC-38 (CCD63396.1); human sequences: GABRA2 (P47869.2), GABRG2 (P18507.2), GABRB3 (P28472.1), GABRR1 (P24046.2), GLYRA1 (CAA36257.1), CHNRA7 (P36544.5), 5 HT3A

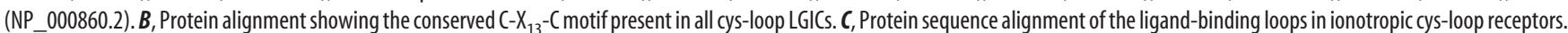
Alignments were made with clustalX. Residues implicated in GABA binding by $\alpha 1$ (asterisks, loops D and E) and $\beta 2$ (black circles, loops A-C) subunits are indicated (Sigel et al., 1992; Amin and Weiss, 1993; Westh-Hansen et al., 1997, 1999; Boileau et al., 1999, 2002; Wagner and (Zajkowski, 2001; Beg and Jorgensen, 2003). D, Alignment of the M2 region shows that LGC-35 is nearly identical to EXP-1. Residues determining ion selectivity are boxed in red and numbered.

EXP-1 $(-5 \mathrm{mV})$, and significantly different from the UNC-49B GABA receptor $(-30 \mathrm{mV})$, a chloride-selective channel (Fig. $2 D$, Control, solid black line) (Bamber et al., 1999; Beg and Jorgensen, 2003). Replacement of extracellular chloride with gluconate did not markedly shift the reversal potential $(-13 \mathrm{mV})$. Additionally, agonist-evoked inward current was not abolished, suggesting that LGC-35 is not permeable to anions (Fig. $2 \mathrm{D}, \mathrm{Cl}^{-}$free, blue line). In contrast, replacement of extracellular sodium with $\mathrm{N}$-methylD-glucamine (NMDG) shifted the reversal potential to $-77 \mathrm{mV}$, near the predicted potassium equilibrium potential in $X$. laevis oocytes (Weber, 1999), and abolished GABA-evoked inward whole-cell currents (Fig. $2 \mathrm{D}, \mathrm{Na}^{+}$free, red line). Last, when extracellular sodium was replaced with equimolar potassium, robust inward currents were observed with a reversal potential of 6 $\mathrm{mV}$ (Fig. $2 \mathrm{D}, \mathrm{K}^{+}$, green line), demonstrating that LGC-35 is permeable to both sodium and potassium. Together, the electro- physiological data demonstrate that LGC-35 is a GABA-gated nonselective cation channel.

\section{LGC-35 localization}

To identify cells expressing $\operatorname{lgc}$-35, we built a transcriptional reporter using the $\sim 3 \mathrm{~kb} \lg \mathrm{c}$-35 promoter attached to the coding region of a red fluorescent protein (Plgc-35::TagRFP). Reporter expression was observed in a subset of ventral cord motor neurons and head interneurons (Fig. 3A). To visualize LGC-35 protein localization, we made a translational fusion with the coding sequence of GFP inserted into the cytoplasmic loop between M3-M4 in a $7.6 \mathrm{~kb} l g c-35$ genomic fragment (LGC-35::GFP) (Figs. $3 B$ and $4 A$ ). The TagRFP transcriptional reporter and translational GFP-tagged fusion protein exhibited similar cellular distributions, with some important exceptions (Fig. $3 A, B$ ). In both reporter lines, we observed expression in a subset of ventral 
A
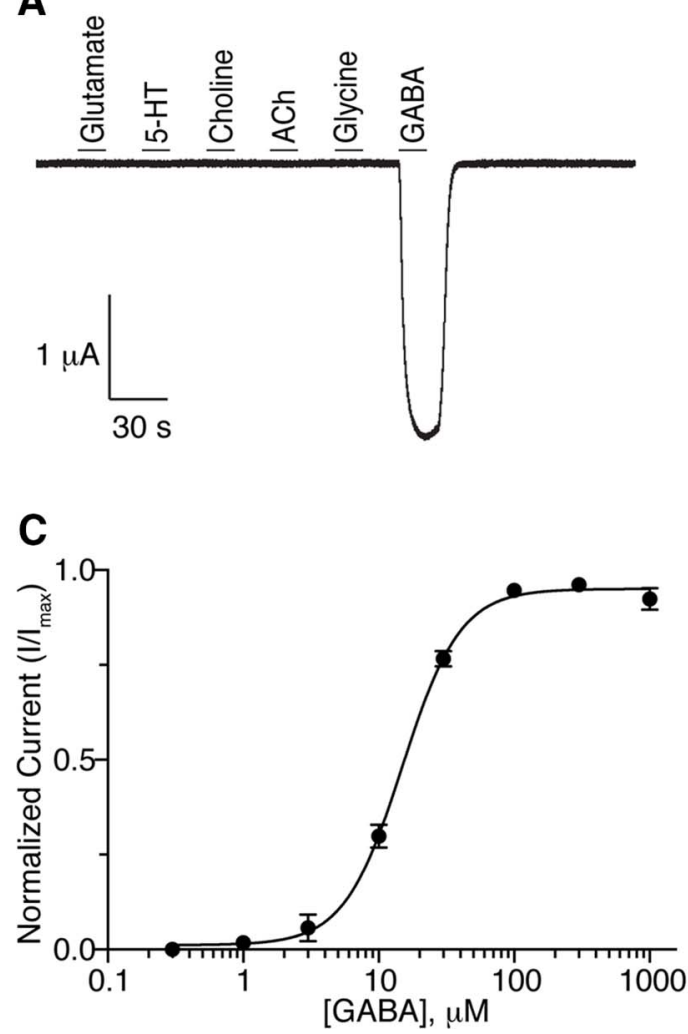

B

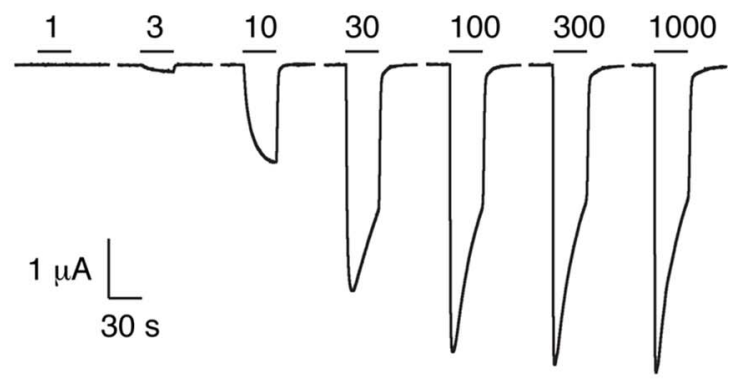

D

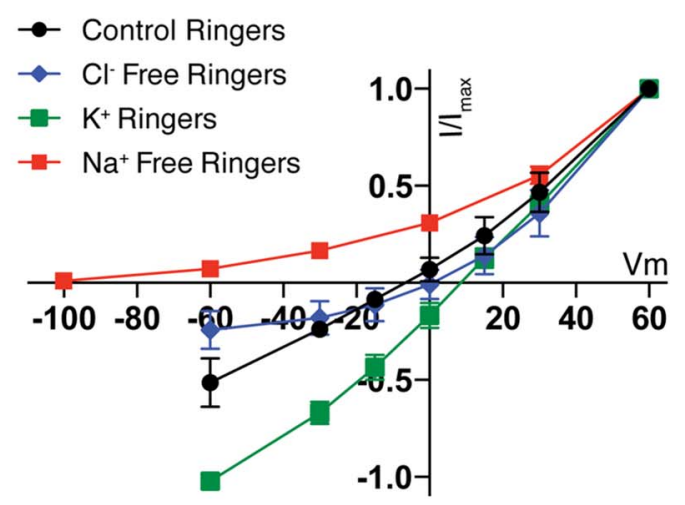

Figure 2. LGC-35 is a GABA-gated cation channel. $A$, Whole-cell currents recorded from $X$. laevis oocytes expressing $L G C-35$ in response to 1 mm: glutamate, serotonin (5-HT), choline, acetylcholine, glycine, and GABA. Black bar represents 10 s application of ligand. Only GABA application evoked whole-cell currents in LGC-35-expressing 00 cytes. $B$, Representative traces of LGC-35 dose-response experiments. Black bar represents 1-1000 $\mu \mathrm{m} \mathrm{GABA}$ application for $30 \mathrm{~s}$. C, Dose-response curve for LGC-35-expressing 00 cytes. 00 cytes expressing LGC-35 were voltage-clamped at $-60 \mathrm{mV}$, and GABA was bath-applied in series (1-1000 $\mu \mathrm{M})$ for $5 \mathrm{~s}$. Points indicate mean current value normalized to maximum value. For $\mathrm{LGC}^{-35}$ receptors, $\mathrm{EC}_{50}=15.04 \pm 1.04 \mu \mathrm{m}$ and $\mathrm{Hill}$ coefficient $=1.9(n=26)$. Error bars indicate SEM. $\boldsymbol{D}$, Current-voltage relations of LGC-35-expressing oocytes. I-V curves determined in control Ringer's solution (Erev $=-10.86 \pm 1.15 \mathrm{mV}, n=$ 12 , black), $\mathrm{Cl}^{-}$(Erev $=-12.94 \pm 2.79 \mathrm{mV}, n=8$, blue), and Na ${ }^{+}$Free Ringer (Erev $=-76.85 \pm 0.65 \mathrm{mV}, n=7$, red), $\mathrm{K}^{+}$Ringer's (Erev $=6.35 \pm 1.26 \mathrm{mV}, n=7$, green). Each point indicates the mean \pm SD.

cord motor neurons (VA, VB, DA, DB) (Fig. $3 A, B$ ), the motor neuron PDA (Fig. $3 F$ ), the tail interneurons DVA and PVT (Fig. $3 F$ ), the head interneurons AIY and AVD (Fig. $3 C, D$ ), and in the head mesodermal cell (Fig. 3C). However, the LGC-35::GFP construct, which includes the introns, exhibited robust expression in the sphincter muscle (Fig. 3E), and all of the acetylcholine ventral cord motor neurons, except the AS and VC class of neurons (Figs. $3 B$ and $5 A$ ). The LGC-35::GFP fusion protein was localized to the plasma membrane as expected, but fluorescence was also observed in the cytoplasm probably due to transgene overexpression (Figs. $3 F$ and $5 A$ ). These data suggest that regulatory elements within the $\operatorname{lgc}$-35 introns are necessary for cell typespecific expression.

To determine the function of $\operatorname{lgc}$-35 in these cells, we characterized two different mutant alleles disrupting the $\operatorname{lgc}$ - 35 gene. $\lg \mathrm{c}-35(\mathrm{tm} 1444)$ is a $\sim 1.3 \mathrm{~kb}$ deletion of the first five exons that removes the extracellular GABA binding domains and cys-loop, and thus likely represents a null allele (Fig. $4 A$ ). To verify that $\operatorname{lgc}$-35(tm1444) is a null allele, we generated a second deletion allele (ox469) that eliminates the entire gene using the MosDEL technique (Frøkjær-Jensen et al., 2010) (Fig. 4A).

\section{LGC-35 mediates contraction of the sphincter muscle}

Expression of LGC-35 in the sphincter muscle suggested that this receptor could play a role in defecation (Fig. $3 E$ ). The defecation motor program in the adult hermaphrodite is a stereotyped behavior initiated every $50 \mathrm{~s}$ when the animal is feeding (Croll, 1975;
Thomas, 1990; Liu and Thomas, 1994). The motor program begins with a posterior body contraction, followed by an anterior body contraction and ends with contraction of the enteric muscles (Emc). The EXP-1 excitatory GABA receptor mediates contraction of the intestinal and anal depressor muscles; mutants lacking this gene exhibit a significant reduction in enteric muscle contractions (Emc/cycle) compared with control animals (Fig. $4 B$; wild-type $=99 \%$ vs $\exp -1=31 \%$ Emc/cycle, $p<0.0001)$. However, the defect in exp-1 mutants is milder than complete loss of GABA function, suggesting that a second GABA receptor may be involved. Specifically, mutations in unc-25, which encodes the biosynthetic enzyme for GABA, glutamic acid decarboxylase, cause a severe defect in enteric muscle contractions (Fig. $4 B$; $\exp -1=31 \%$ vs $u n c-25=8.7 \%$ Emc/cycle, $p<0.0001$ ). To determine whether the LGC-35 receptor contributes to enteric muscle contractions, we generated double mutants. $\mathrm{Mu}-$ tants lacking both receptors $(\lg c-35$ exp-1) exhibited decreased enteric muscle contractions compared with exp-1 single mutants (Fig. $4 B$; $\exp -1=31 \%$ vs $\operatorname{lgc}-35(\operatorname{tm} 1444) \exp -1=12 \%$ or $\operatorname{lgc}$ 35 (ox469) $\exp -1=13 \%$ Emc/cycle, $p<0.0001$ ) and were not significantly different from unc-25 single mutants (Fig. $4 B$; lgc35(tm1444) $\exp -1 p=0.24$ or $\lg c$-35(ox469) $\exp -1 p=0.06$ ). Additionally, RNA interference knockdown of $\operatorname{lgc}-35$ recapitulated the genetic loss-of-function experiments (Fig. 4B). Finally, LGC-35::GFP transgene expression in the double mutant rescued defecation to $\exp -1$ single-mutant levels, demonstrating that the enhanced phenotype was specifically due to the loss of $\operatorname{lgc}$-35 (Fig. 

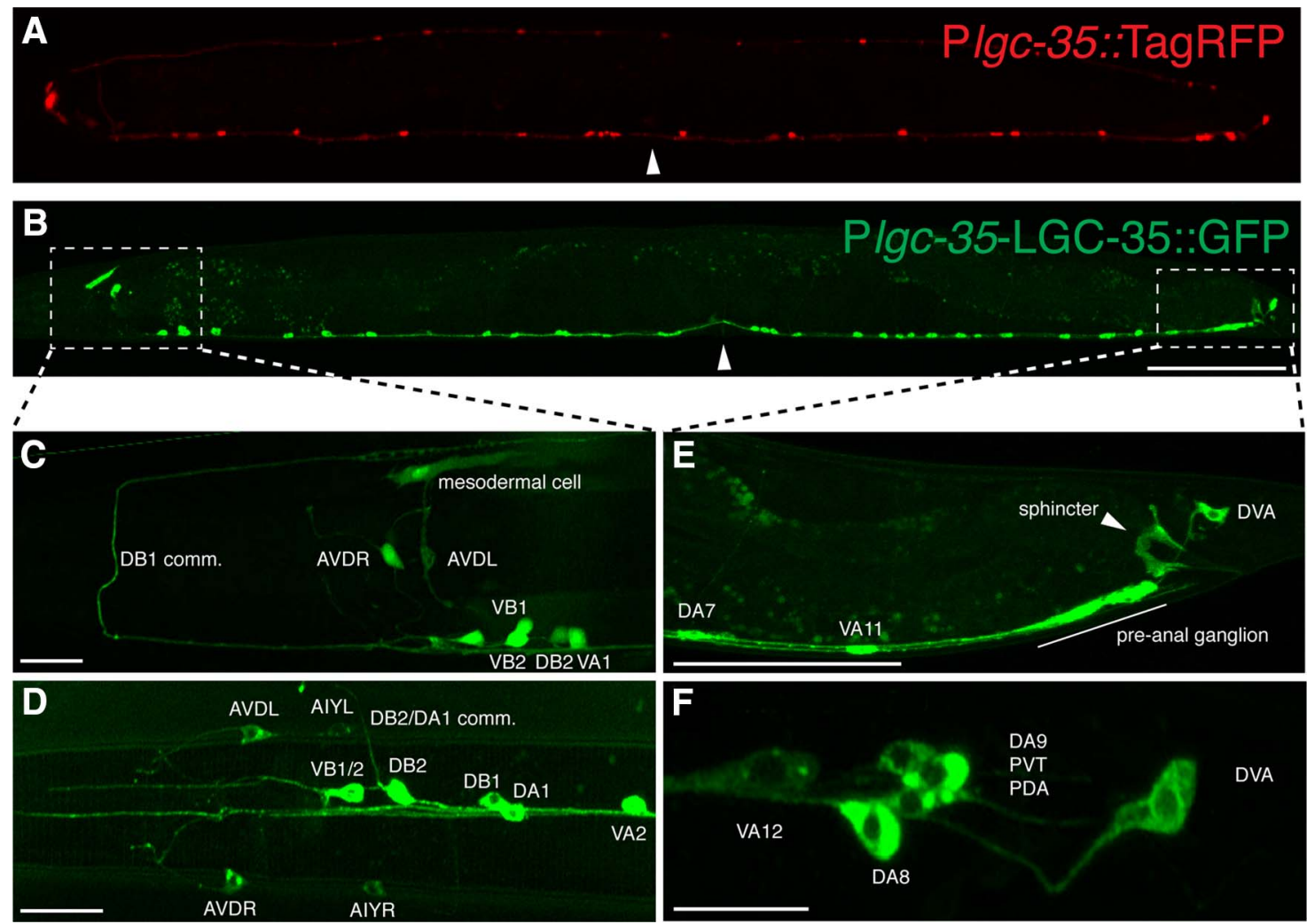

Figure 3. LGC-35 is expressed in the sphincter and a subset of ventral cord motor neurons. $A$, Transcriptional reporter. Plgc-35::TagRFP is expressed in a subset of VA, VB, and DB acetylcholine motor neurons anterior to the vulva, and in a subset of VA and DA acetylcholine motor neurons posterior to the vulva. This construct lacks introns. $B$, Translational reporter. LGC-35::GFP is expressed in all acetylcholine motor neurons (VA, VB, DA, DB), except the AS and VC class. This construct includes all introns. C, Plgc-35::TagRFP (pseudocolored green) expression in the adult nerve ring. In addition to the ventral cord motor neurons, lgc-35 is expressed in the AVD neurons and the head mesodermal cell. D, LGC-35::GFP expression is observed in the AIY and AVD interneurons and commissural (comm.) processes. $\boldsymbol{E}$, Close-up of posterior hermaphrodite tail region. White arrowhead indicates LGC-35::GFP sphincter muscle expression. $\boldsymbol{F}$, High magnification of the hermaphrodite tail. LGC-35::GFP is expressed in DVA, PDA, and PVT neurons. Scale bars: $\boldsymbol{A}, \boldsymbol{B}, 100 \mu \mathrm{m} ; \boldsymbol{C}-\boldsymbol{F}, 10 \mu \mathrm{m}$. Images are lateral views of an adult hermaphrodite; anterior is to the left. Arrowhead indicates the location of the vulva. $\boldsymbol{B}$, White boxes represent the imaged areas in $\boldsymbol{C}-\boldsymbol{F}$.

$4 B ; \exp -1=31 \%$ vs $\lg c-35(t m 1444) \exp -1 ; E x[\mathrm{LGC}-35:: \mathrm{GFP}]=$ $29 \%$ Emc/cycle, $p=0.81)$. These findings demonstrate that LGC-35 and EXP-1 together mediate GABA-dependent enteric muscle contraction.

The enteric muscles are coupled by gap junctions and appear to contract almost simultaneously. However, analysis of the related nematode Oscheius myriophila and high-speed videos of $C$. elegans indicates that there is a distinct order to the contraction (J. Delafield-Butt and E. Jorgensen, personal communication). The intestinal muscles contract first and fill the rectum with intestinal fluid. Contraction of the sphincter muscle seals the rectum, preventing reflux. Once the intestine is sealed, contraction of the anal depressor muscle opens the anus, and gut contents are expelled. Because of the close temporal activation of the enteric muscles, it is difficult to observe contraction of the sphincter muscle when the intestinal and anal depressor muscle contractions are present. Therefore, we used the exp-1 mutant background to specifically isolate sphincter muscle contraction because these mutants rarely exhibit intestinal and anal depressor contractions. High-speed video analysis revealed sphincter muscle contraction in exp-1 mutants $(n=12$; Movie 1$)$, confirming that EXP-1 is not required for this muscle contraction. By contrast, in $\operatorname{lgc}-35$ exp-1 double mutants, the sphincter muscle did not contract, and the rare expulsions that occurred were explosive, uncoordinated, and were not accompanied by sphincter muscle contraction $(n=15$; Movie 2). These behavioral data demonstrate that LGC-35 specifi- cally mediates GABA-induced contraction of the sphincter muscle and contributes to the contraction of all enteric muscles during the defecation motor program (Fig. 4C).

\section{GABA spillover stimulates acetylcholine release in the locomotory circuit}

To confirm that $\operatorname{lgc}$-35 is expressed in the acetylcholine motor neurons, we created double-transgenic animals in which the ventral cord acetylcholine motor neurons express the fluorescent protein mCherry under the control of the acr-2 promoter (Pacr-2::mCherry). acr-2 is expressed in VA, VB, DA, and DB acetylcholine motor neurons (Jospin et al., 2009). In Plgc-35::LGC-35::GFP; Pacr-2::mCherry double transgenics, colocalization of fluorescent reporter proteins was observed, verifying that $\lg \mathcal{C}$-35 is expressed in these acetylcholine motor neurons (Fig. 5A). To determine whether $\operatorname{lgc}$-35 is expressed in GABA motor neurons, Plgc-35::LGC-35::GFP-expressing animals were crossed into a strain expressing the fluorescent protein mCherry under the control of the unc-47 promoter (Punc-47::mCherry), which labels all 26 GABA motor neurons (Jin et al., 1999). We observed no colocalization between $\operatorname{lgc}$-35 and $u n c-47$ expression in these animals, confirming that LGC-35 is expressed in ventral cord acetylcholine, but not GABA motor neurons (Fig. 5B)

Both diffuse and punctate localization of the LGC-35::GFP translational fusion protein was observed in the dorsal and ventral nerve cords and in the acetylcholine motor neuron cell bodies (Figs. $3 \mathrm{~A}$ 
A

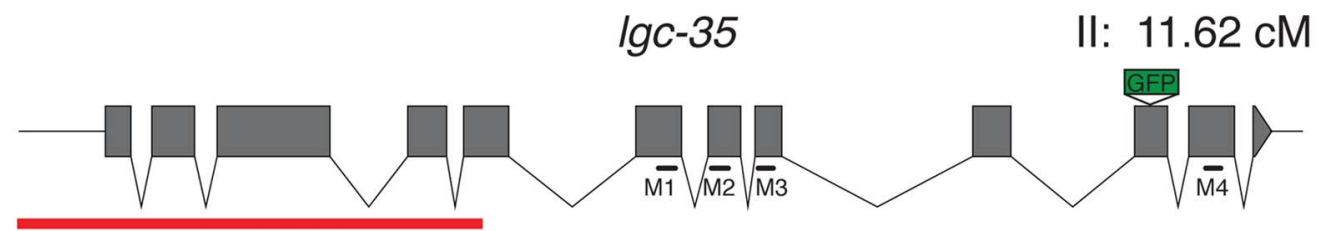

$\operatorname{tm} 1444$

\section{ox469}
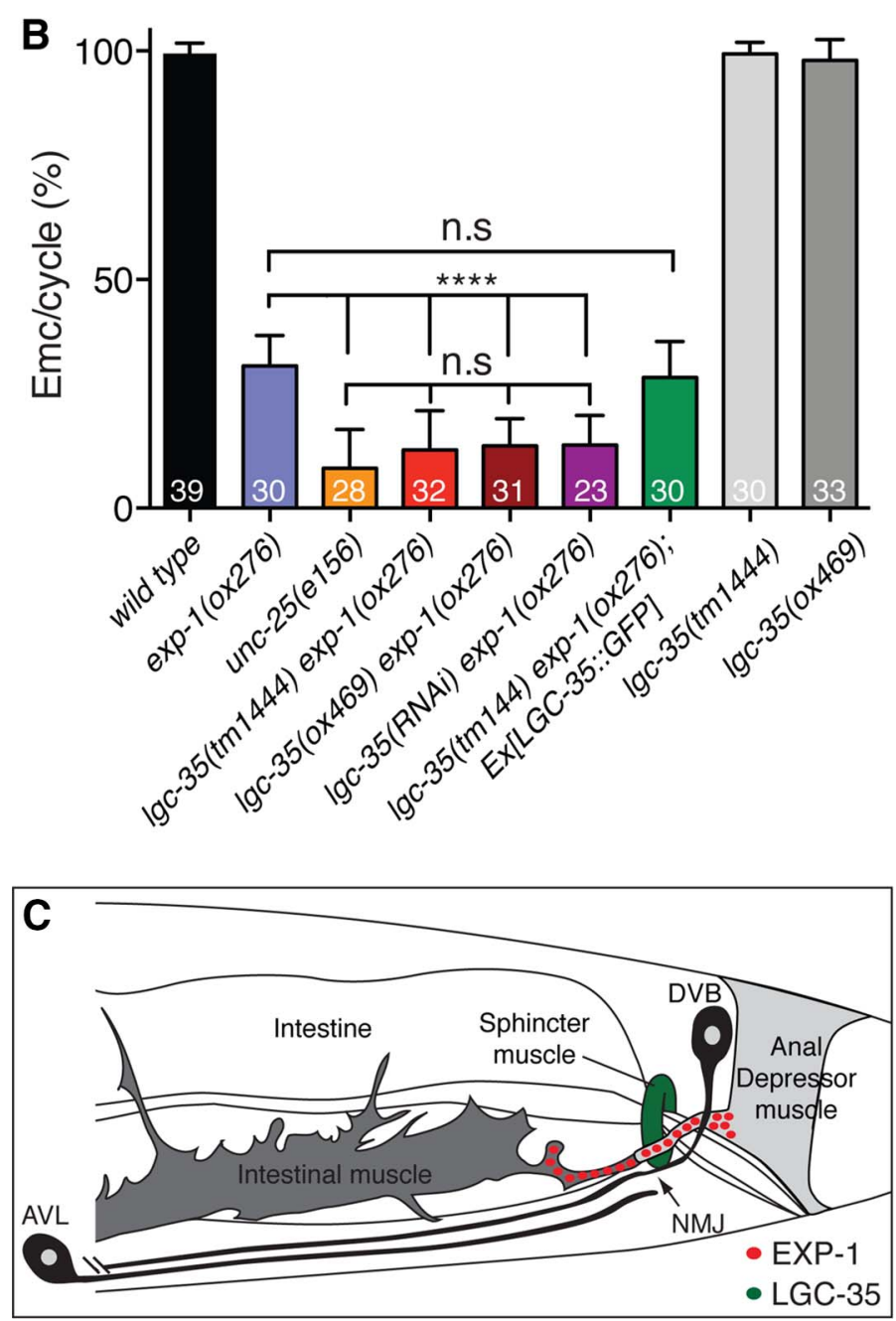

Figure 4. Igc-35 mediates contraction of the sphincter muscle. $A$, Exon-intron structure of the lgc-35 genomic locus. Red bars represent the deletion extent for each allele. Black bars represent transmembrane domain (M1-M4) location. The GFP insertion site is shown. B, Igc-35(tm1444 or ox469) exp-1(ox276) double mutants are more defective in enteric muscle contractions than exp-1(ox276) mutants alone. Enteric muscle contractions per posterior body contraction were scored to determine successful enteric muscle contractions per defecation cycle (Emc/cycle). Eleven defecation cycles were scored from young adult hermaphrodites for each genotype. The strain lgc-35(tm 1444) exp-1(0x276); Ex[LGC-35::GFP] contains an extrachromosomal genomic lgc-35::gfp rescuing array (oxEx1291). Percentage of Emc/Cycle (mean \pm SEM): wild-type $=99.5 \pm 0.36 \%$, exp-1(ox276) $=31.2 \pm 1.2 \%$, unc-25(e156) $=8.68 \pm 1.6 \%, l g c-35($ tm 1444$)$ exp-1(ox276) $=12.7 \pm 1.53 \%, l g c-35($ ox469) exp-1(ox276) $=13.65 \pm 1.06 \%$, lgc-35(RNAi) exp-1(ox276) $=13.74 \pm 1.4, \operatorname{lgc}-35(\operatorname{tm} 1444)$ exp-1(ox276); Ex[LGC-35::GFP] $=28.6 \pm 1.4 \%, \operatorname{lgc}-35(\operatorname{tm} 1444)=99.3 \pm 0.46 \%, \operatorname{lgc}-35($ ox469) $=97.9 \pm$ $0.79 \%{ }^{* * * *} p<0.0001$ (one-way ANOVA with Tukey posthoc used for multiple comparison). n.s, Not significant. Error bars indicate SEM. The number of animals scored for each genotype is shown at the bottom of each bar. C, Schematic model of the enteric muscles. Red circles represent clustered EXP-1 receptors at the AVL/DVB synapse. The sphincter muscle is colored green to illustrate diffuse and nonclustered LGC-35 expression. Figure adapted with permission (Beg and Jorgensen, 2003).

and $5 A, C)$. To determine whether LGC-35 is juxtaposed to GABA synapses, we labeled the synaptic vesicle protein synaptobrevin with TagRFP in GABA neurons (Punc-47::SNB-1::TagRFP). Synaptobrevin distribution was punctate, marking GABA neuromuscular junctions along the nerve cord (Bamber et al., 1999). LGC-35::GFP puncta were not juxtaposed to GABA synapses but were rather lo- calized to intersynaptic regions along the nerve cord between the GABA synapses (Fig. 5C). These data suggest that GABA spillover from GABA neuromuscular junctions activates LGC-35 on acetylcholine motor axons.

The presence of LGC-35 on acetylcholine motor neurons suggests that GABA stimulates acetylcholine release onto mus- 
Acetylcholine Motor Neurons
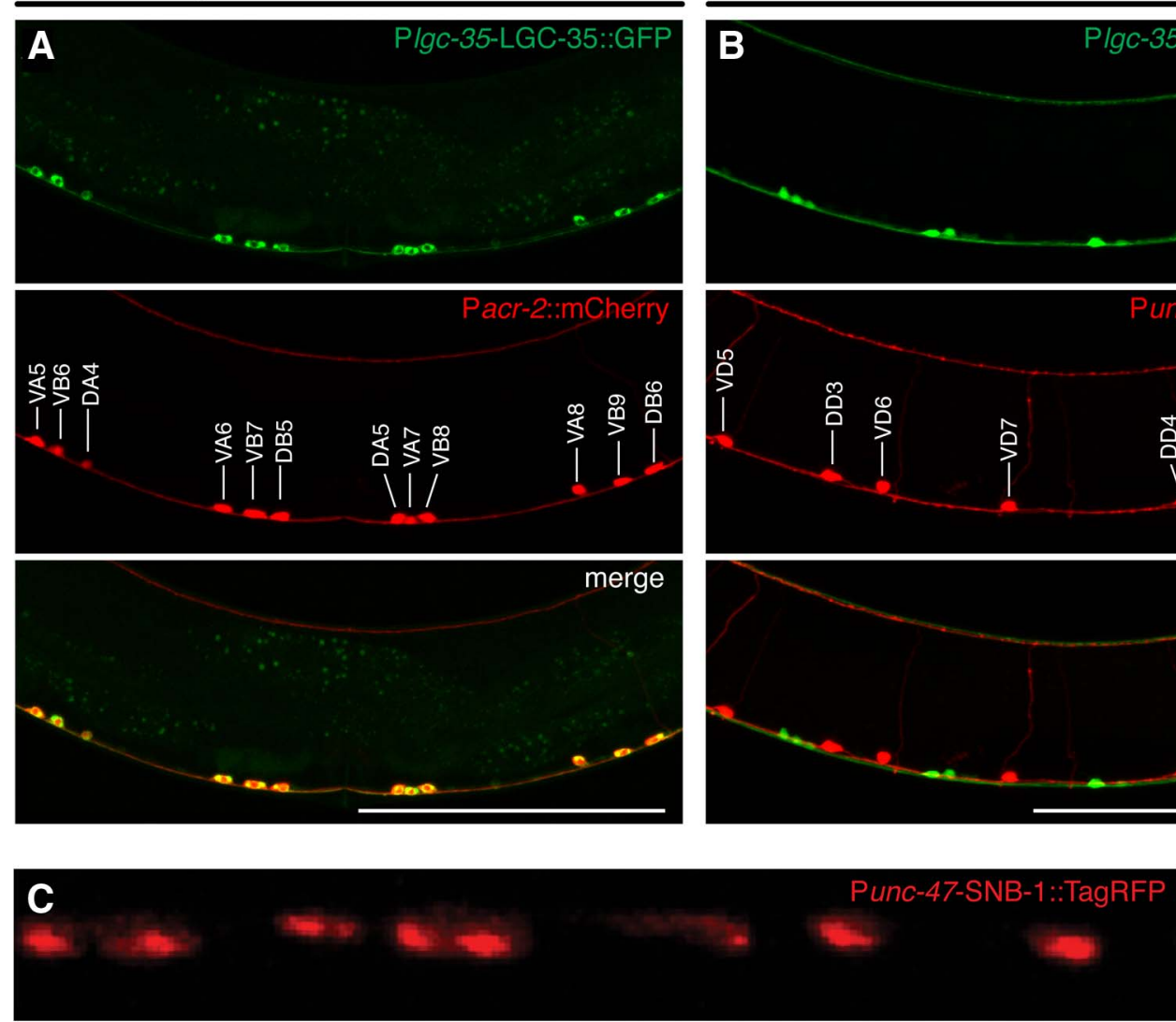

PlgC-35-LGC-35::GFP

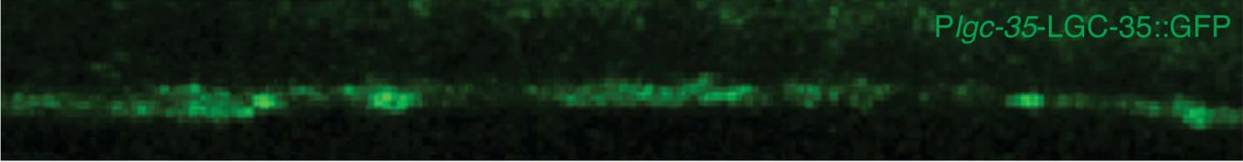

merge

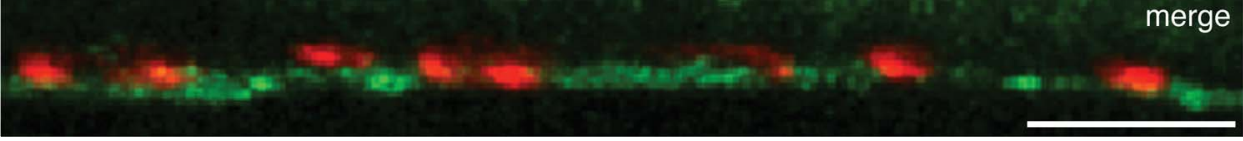

Figure 5. Igc-35 is expressed in ventral cord acetylcholine motor neurons. $A$, Lateral view of LGC-35::GFP expression in Pacr-2::mCherry background. Colocalization is seen in all acr-2-expressing acetylcholine motor neurons (DA, DB, VA, VB). Lateral view of the vulva region of an adult hermaphrodite; anterior is to the left and dorsal is up. The acetylcholine motor neurons are labeled in the middle panel. $\boldsymbol{B}$, Lateral view of LGC-35::GFP motor neuron expression in Punc-47::mCherry background. LGC-35::GFP (green) is not localized to GABA motor neurons (red). Lateral view of the vulva region of an adult hermaphrodite; anterior is to the left and dorsal is up. The GABA motor neurons are labeled in the middle panel. C, LGC-35::GFP is localized to intersynaptic regions. Punc-47::SNB-1::TagRFP (red, top panel) coinjected with Plgc-35::LGC-35:GFP (green, middle panel). Lateral view of the dorsal cord. Scale bars: $A, B, 100 \mu \mathrm{m} ; \boldsymbol{C} ; 10 \mu \mathrm{m}$.

cles and that there may be deficits in acetylcholine transmission in the absence of LGC-35. To determine whether acetylcholine release is decreased in the absence of LGC-35, we assayed the sensitivity of $\operatorname{lgc}-35$ mutants to aldicarb, an acetylcholinesterase inhibitor (Mahoney et al., 2006). Both $\operatorname{lgc}$-35 mutant strains were resistant to aldicarb, suggesting a presynaptic defect in neuronal excitability or neurotransmitter release (Fig. 6A). To demonstrate that this phenotype was specifically due to loss of LGC-35, we rescued the sensitivity to aldicarb by transgenic expression of LGC-35::GFP (Fig. 6A). These pharmacological data indicate a decrease in acetylcholine transmission at neuromuscular junctions in the mutants. To determine whether this decrease in neurotransmission affects locomotion, we performed thrashing assays in liquid. lgc-35 mutants not only exhibited a significant decrease in the number of body bends but also displayed uncoordinated body bending compared with wild-type controls (Fig. 6B; data not shown). These phenotypes were rescued by transgene expres- sion of LGC-35::GFP (Fig. 6B), suggesting that loss of LGC-35 results in an imbalance in the excitation to inhibition ratio within the locomotor circuit.

To determine the function of $\operatorname{lgc}-35$ in locomotory behavior, we analyzed $\operatorname{lgc}$ - 35 mutants crawling on agar using a computerized worm tracker. Animals were evaluated under high magnification during normal, unstimulated movement on food. $\operatorname{lgc}$-35 mutants spent comparable amounts of time moving forward and backward compared with wild-type controls (data not shown). However, the animals moved faster, and the amplitude of body bends was increased in $l g c-35$ mutants; both phenotypes were rescued by transgene expression of LGC-35::GFP (Fig. 6C,D). Together, these data suggest that $\lg c$-35 functions in motor neurons to regulate animal locomotion.

\section{LGC-35 is involved in male spicule eversion}

After hatching, larval C. elegans hermaphrodites and males are largely indistinguishable. However, in the fourth larval stage 


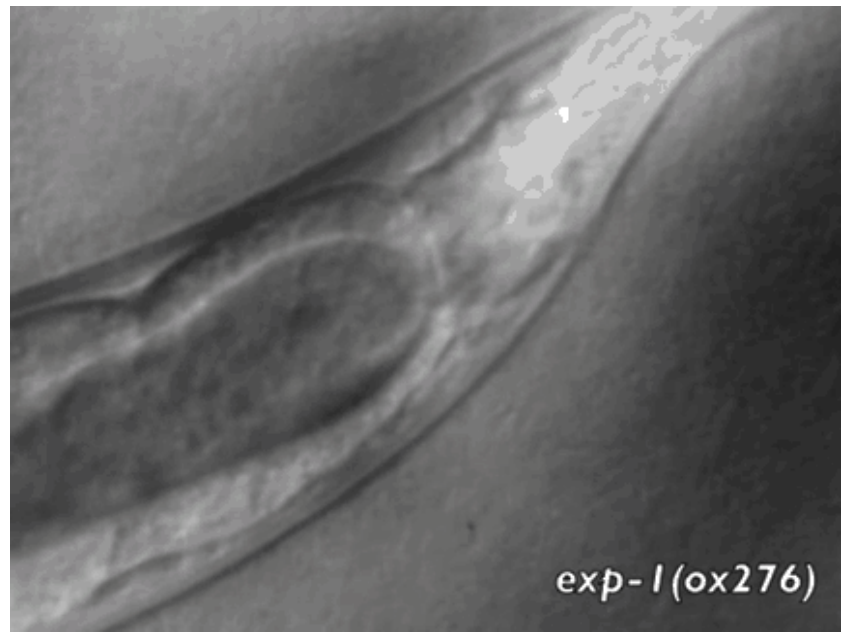

Movie 1. Visualizing sphincter muscle contraction in exp-1(ox276) mutants. Sphincter contraction with no expulsion. exp-1(ox276) mutant recorded during a nonexpulsive cycle. The sphincter contracts (red arrow) after the posterior body contraction in the absence of exp-1 mediated anal depressor contraction and expulsion $(n=12)$.

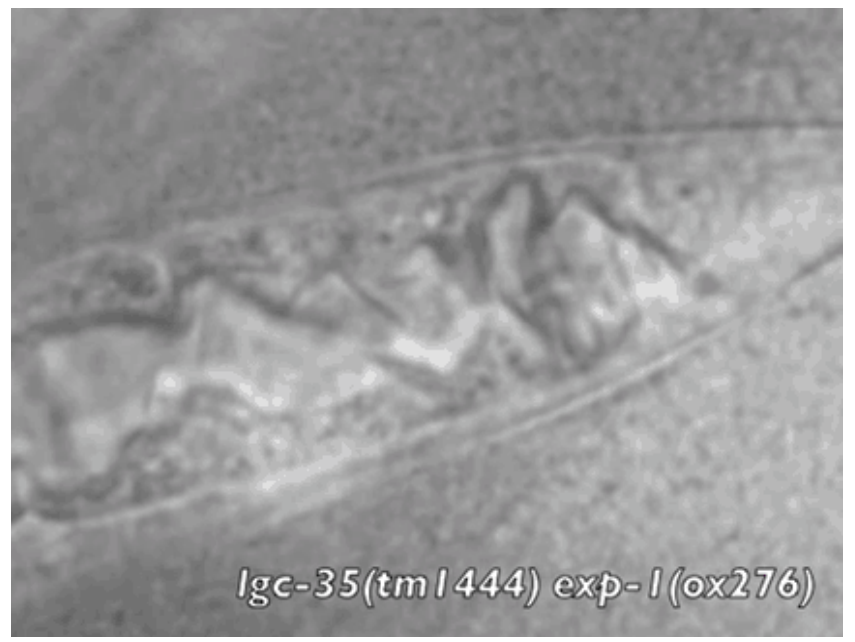

Movie 2. Sphincter muscle does not contract in lgc-35 mutants. In Igc-35(tm1444) exp1(ox276) double mutants, expulsions rarely occurred and were explosive. Sphincter contraction was never observed (red arrow, $n=15$ ). This video is recorded during an expulsive cycle; the posterior intestine swells and the rectum fills with food. The sphincter is passive and flaccid. The anal depressor contracts and opens the anus. The sphincter fails to contract, and the gut contents explode from the anus.

(L4), male-specific neurons and copulatory muscles are generated and the enteric muscles are extensively remodeled. Specifically, the anal depressor attaches to the spicule protractor and the sphincter muscle becomes enlarged and attaches to the dorsal surface of the body wall. We generated males expressing either transcriptional or translational GFP fusions to determine whether $\operatorname{lgc}$-35 is expressed in male-specific muscles and neurons. In contrast to hermaphrodites, $\lg c$ - 35 is not expressed in any of the male enteric muscles, including the sphincter muscle, suggesting that it does not play a role in defecation in adult males (Fig. $7 A, B$ ). Like hermaphrodites, adult males expressed $\operatorname{lgc}$-35 in acetylcholine motor neurons, the head mesodermal cell, and in the head interneurons AIY and AVD (data not shown). In the male tail, $l g c-35$ is expressed in sensory rays $2,3,4,5$, and 9, the SPV neurons, and the oblique muscles (Fig. $7 A-C$ ).

Consistent with this expression pattern, GABA neurons are known to innervate these cells. The vesicular GABA transporter (unc-47) is expressed in the male specific PCB, PCC postcloacal sensilla neurons, and the SPC proprioceptive motor neurons (Fig. $7 C, D$ ). Interestingly, in addition to expressing the GABA transporter, these motor neurons also express the vesicular acetylcholine transporter UNC-17 (Garcia et al., 2001) (Fig. 7D). It is likely that these sensorimotor neurons redundantly use GABA and acetylcholine to induce muscle contraction during copulation (Jarrell et al., 2012). The SPC neurons make chemical synapses directly with the spicule muscles and presumably act via a different GABA receptor than LGC-35 (Fig. 7D). The PCB and PCC neurons make chemical synapses with the LGC-35expressing oblique muscles (Fig. 7D). During intromission, the postcloacal PCB and PCC neurons mediate insertion of the spicules into the vulva by initially stimulating oblique muscle contraction. In turn, the oblique muscles transduce the signals to the spicule-associated sex muscles through electrical junctions (Liu and Sternberg, 1995; Garcia et al., 2001; Liu et al., 2011; Jarrell et al., 2012) (Fig. 7D).

The expression of LGC-35 in male-specific muscles and neurons suggests that the receptor might play a role in male mating. We assayed mating efficiency by placing single males with four wild-type hermaphrodites and then removed the male after four time points $(1,3,6$, and $24 \mathrm{~h})$. With the exception of the $6 \mathrm{~h}$ time point, lgc-35(tm1444) him-8(e1489) double mutants males were not significantly different from control him-8(e1489) singlemutant males for the percentage of cross progeny sired (Fig. 7E); nor was male potency in aged animals affected in $\operatorname{lgc}$-35 mutants. Specifically, single males, aged 1-6 d, were paired with a young adult pha-1(ts) hermaphrodite, and the presence of any cross progeny was scored $3 \mathrm{~d}$ later. The virility of $l g c-35$ males diminished at a similar rate as control males over $6 \mathrm{~d}$ (Fig. $7 F$ ), suggesting that $\lg c$-35 does not play an overt role in male mating ability or potency.

To determine whether there were more subtle defects in the male, we examined spicule extension and retraction between mating events. During periods between sex, the male generally keeps his spicules inside his tail. However, at a low probability, he will spontaneously protract his spicules during defecation (Garcia and Sternberg, 2003). In rare cases, the spicules become permanently everted in adult wild-type males (5.7\% everted) or from the strain him-8, which produces males at high frequency $(9.8 \%$ everted) (Fig. $7 G)$. Spicule eversion is significantly reduced by the loss of the excitatory GABA receptor LGC-35 compared with him-8 controls (1.6\% everted in lgc-35; him-8, $p<0.05)$ (Fig. $7 G$ ). By contrast, spicule eversion is greatly exacerbated by the loss of the inhibitory GABA receptor UNC-49 compared with him-8 controls $(40.4 \%$ everted spicules in unc-49; him-8, $p<$ 0.0001 ) (Fig. $7 G$ ). Moreover, loss of $\operatorname{lgc}$ - 35 completely suppressed the everted spicule phenotype observed in unc-49 mutants $(1.2 \%$ in $\operatorname{lgc}$-35; unc-49; him-8), and suppression of spicule eversion was reversed by transgene expression of LGC-35::GFP (34.1\% in $\operatorname{lgc}$ 35; unc-49; him-8; Ex[LGC-35::GFP]) (Fig. 7G) . Together, these data suggest that inhibitory GABA signaling inhibits spicule extension, whereas excitatory GABA signaling stimulates spicule extension, probably via GABA inputs into the spicule-associated muscles, which is in part formed from remodeled enteric muscles during the L4 stage.

\section{Discussion}

We found that the GABA receptor LGC-35 acts as an excitatory ion channel at the sphincter muscle in hermaphrodites, at the spicule protractor in males, and on acetylcholine motor neurons involved in locomotion. We discuss these results in regard to the 
A

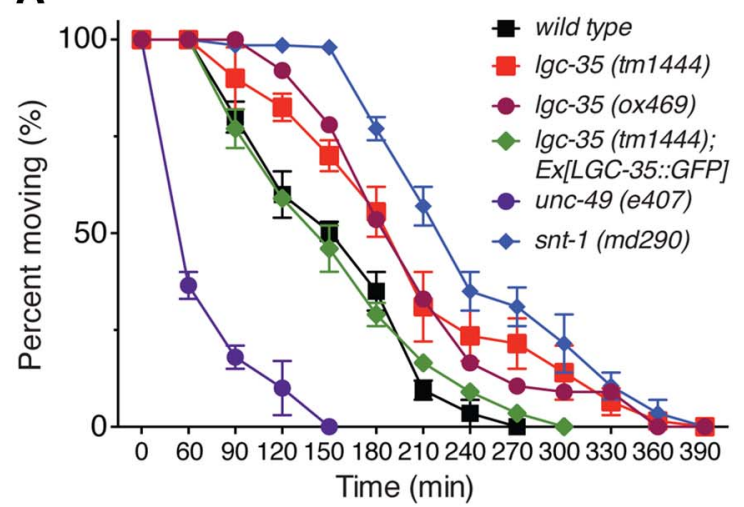

C

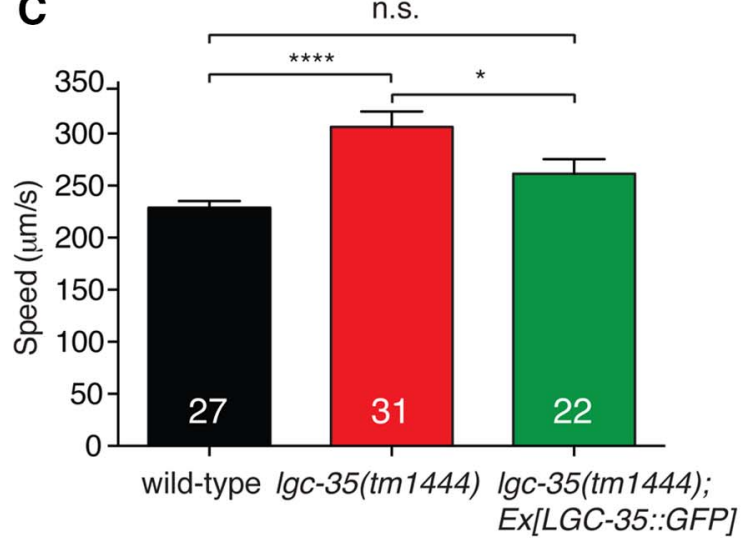

B

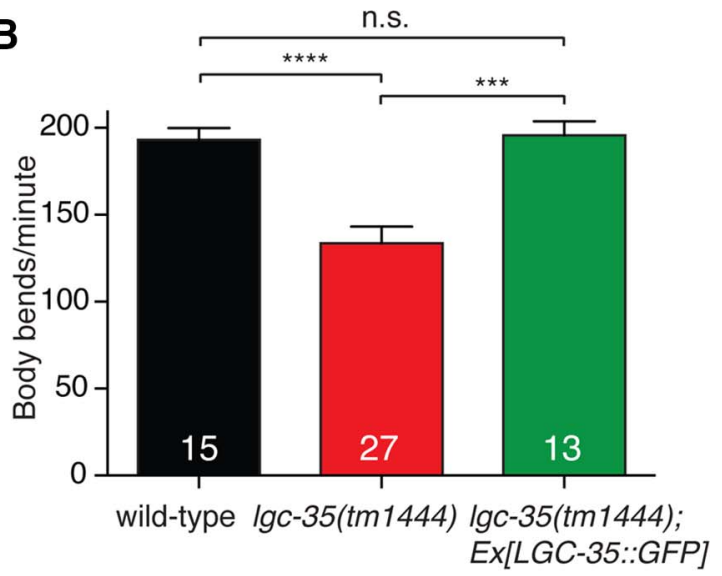

D

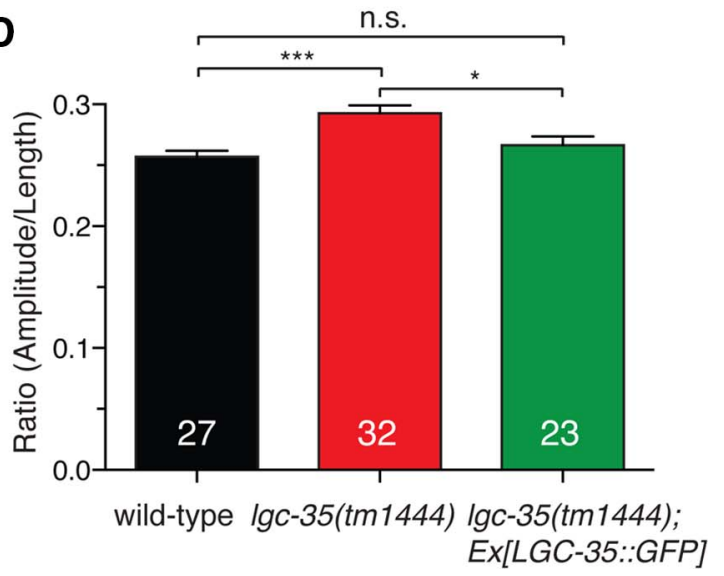

Figure 6. $\operatorname{lgc}-35$ mutants have altered locomotion and neuromuscular transmission. $A$, lgc-35 mutants are resistant to aldicarb, an acetylcholinesterase inhibitor. $\operatorname{lgc}-35$ mutants (tm 1444 and ox469) are resistant to the paralyzing effects of aldicarb compared with wild-type. A known hypersensitive mutant unc-49(e407) and resistant mutant snt-1(md290) were used as controls. Data are mean \pm SEM; $n=30$ animals, 3 plates per genotype. Aldicarb resistance in $1 g(-35(\operatorname{tm} 1444)$ mutants is rescued by LGC-35::GFP transgene expression. $\boldsymbol{B}$, Liquid thrash assays were used to assess neuromuscular transmission and coordination. $\operatorname{lgc}-35(\mathrm{tm} 1444)$ mutants exhibited a significant decrease in the number of body bends per minute compared with wild-type controls: $\operatorname{lgc}(-35(\mathrm{tm} 1444)=133 \pm$ 9.7 versus wild-type $\left.=193 \pm 6.9{ }^{* * * *} p<0.0001\right)$, which was rescued by LGC-35::GFP transgene expression: $\operatorname{lgc}-35($ tm1444); Ex[LGC-35::GFP] $=195 \pm 7.9 . p=0.64$, compared with the wild-type. ${ }^{* * *} p=0.0003$, compared with $\operatorname{lgc}-35(\mathrm{tm} 1444)$. C, lgc-35 mutants move with increased speed compared with the wild-type controls: $\operatorname{lgc}-35(\mathrm{tm} 1444)=306 \mu \mathrm{m} / \mathrm{s}$ versus wild-type $=229 \mu \mathrm{m} / \mathrm{s}$. ${ }^{* * * *} p<$ 0.0001. This increase is rescued by transgenic expression of LGC-35::GFP (262 $\mu \mathrm{m} / \mathrm{s}$ vs wild-type, $p=0.19)$. ${ }^{*} p=0.039$, compared with $\operatorname{lgc}-35(\mathrm{tm} 1444)$ mutants. D, lgc-35(tm1444) mutants exhibit an increased body bend amplitude compared with the wild-type controls: $\lg \left(-35(\operatorname{tm} 1444)=0.29\right.$ versus wild-type $=0.25 .{ }^{* * *} p=0.0002$. This increase in $\operatorname{lgc}-35(\mathrm{tm} 1444)$ mutants is rescued by transgenic expression of LGC-35::GFP ( $0.26 \mu \mathrm{m}, p=0.57$, compared with the wild-type). ${ }^{*} p=0.012$, compared with lgc-35(tm1444) mutants. The body bend amplitude ratio (Amplitude/Length) is shown. One-way ANOVA with Tukey post hoc analysis was used for multiple comparison, and the $p$ values are indicated for each condition. n..., Not significant $(p>0.05)$. The number of animals tested for each genotype or assay is shown at the bottom of each bar.

structure and evolution of ligand-gated ion channels, the relationship of EXP-1 and LGC-35 in the control of muscle contraction, and finally the role of LGC-35 in spillover transmission between motor neurons.

\section{How did LGC-35 acquire cation selectivity?}

How did GABA-gated cation channels evolve? Phylogenetic analysis demonstrates that these receptors are more closely related to other GABA receptors than they are to acetylcholine or serotonin receptors (Fig. $1 A, C$ ). However, the M2 domain is divergent from other cation channels indicating that there are multiple solutions for generating cation permeability (Fig. 1D).

Mutational studies have demonstrated that pore geometry, size, and electrostatic charge are critical features that determine cys-loop receptor ion selectivity (Jensen et al., 2005a). Changes in three residues are sufficient to convert ion selectivity of GABA and glycine receptors from anions to cations: (1) a deletion of the $-2^{\prime}$ proline $\left(\mathrm{P}-2^{\prime} \Delta\right)$; (2) a glutamate substitution at the $-1^{\prime}$ position (A-1'E); and (3) a hydrophobic valine substitution at the $13^{\prime}$ position $\left(\mathrm{T} 13^{\prime} \mathrm{V}\right)$ (Keramidas et al., 2000; Jensen et al., 2002, 2005b; Wotring et al., 2003). The reciprocal changes have also been demonstrated to convert the cation-selective nicotinic acetylcholine and serotonin receptors to anion-selective (Galzi et al., 1992; Corringer et al., 1999; Gunthorpe and Lummis, 2001). Significantly, the single A-1'E point mutation is sufficient to make the glycine receptor (GlyR $\alpha 1)$ permeable to cations (Keramidas et al., 2002), whereas the reverse mutation (E-1'A) renders the serotonin (5-HT3A) receptor nonselective (Gunthorpe and Lummis, 2001).

LGC-35 has several features that differ from canonical inhibitory cys-loop receptors and may explain cation selectivity: (1) a significantly shorter linker region that lacks the conserved PAR motif present in the majority of anion-selective receptors that may alter pore diameter and geometry (Jensen et al., 2005a); (2) a hydrophobic phenylalanine at the $13^{\prime}$ position, which is a hydrophilic threonine in anion-selective receptors (Keramidas et al., 2000); and (3) a negatively charged glutamate residue at the extracellular ring of charge, a position that is predominantly positive in anion channels $\left(19^{\prime}\right)$ and negative in cation channels $\left(20^{\prime}\right)$ (Imoto et al., 1988) (Fig. 1D). Surprisingly, LGC-35 does not 

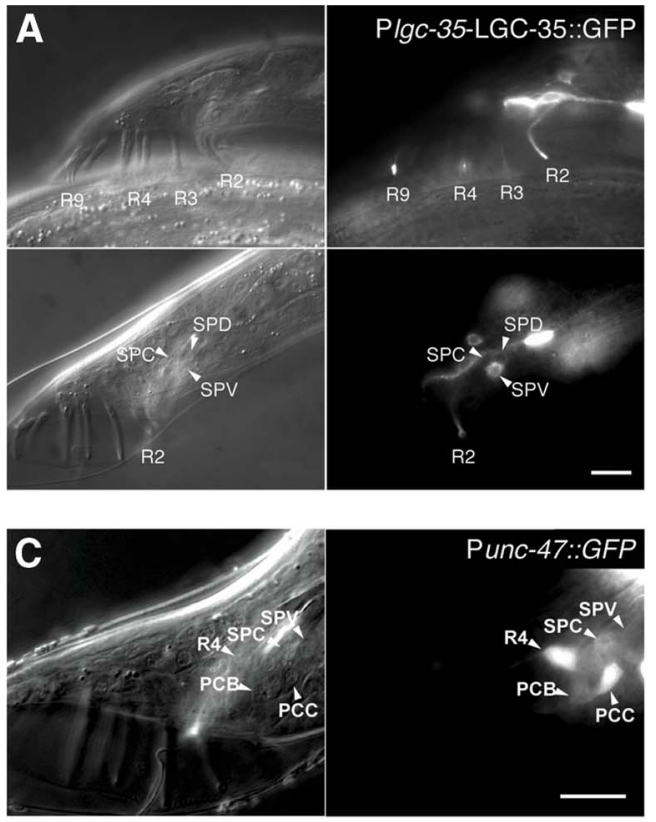

E

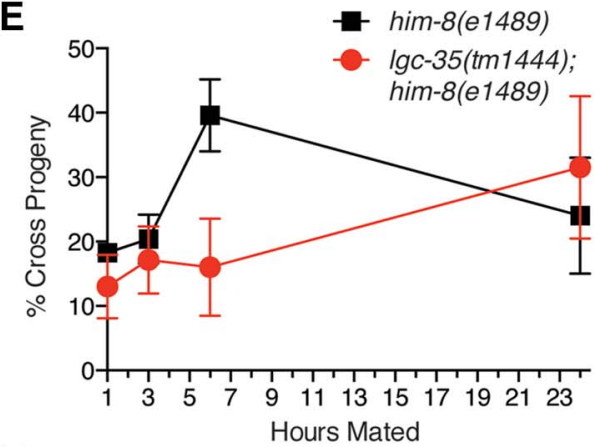

$\mathbf{F}$

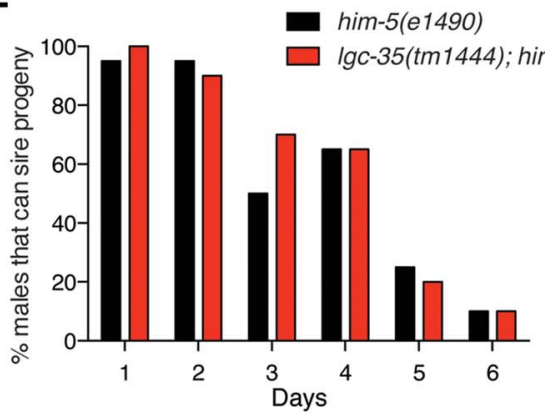

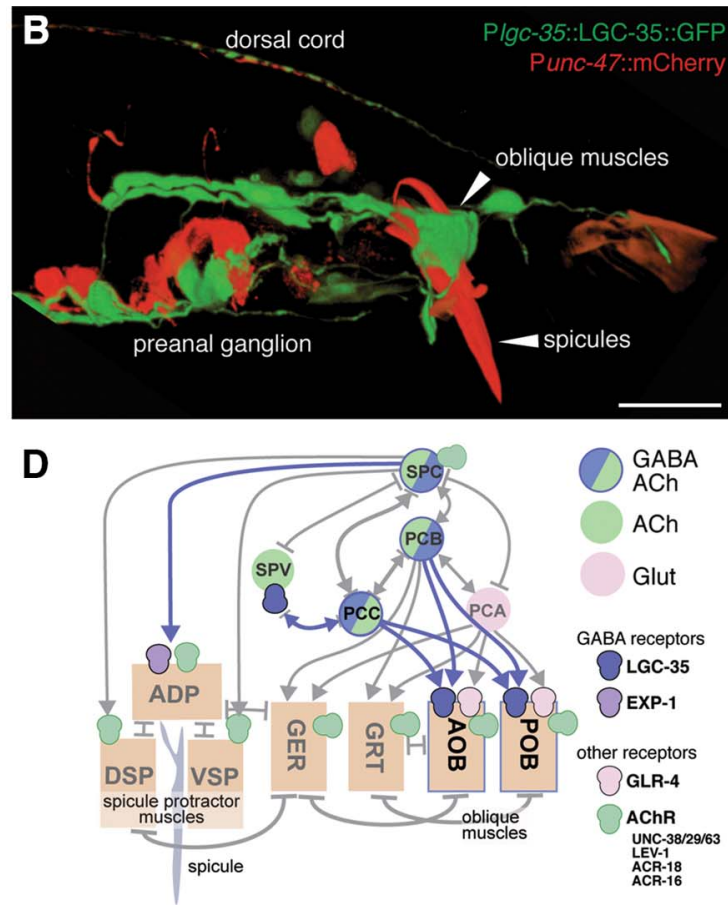

G

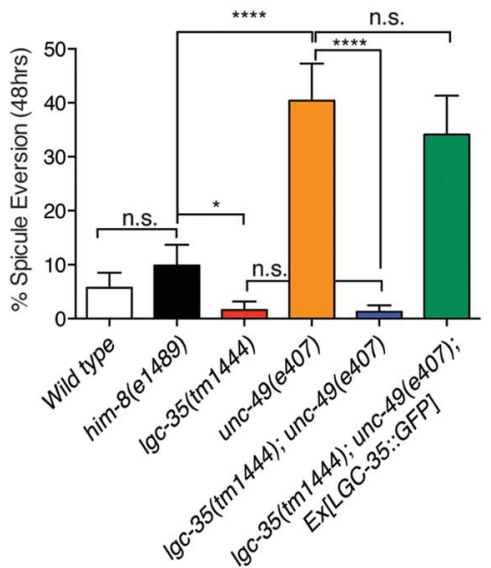

Figure 7. LGC-35 is expressed in male-specific muscles and neurons and is involved in spicule eversion. $A$, Nomarski (left panels) and fluorescence (right panels) images of $L G C-35$ ::GFP expression in the male. Top panels, LGC-35::GFP expression in rays (R) 2,3,4, and 9 (ray 5 expression not shown). Bottom panels, LGC-35::GFP expression in ray 2, the SPV neurons, and possibly the SPD neuron. B, Confocal image of a transgenicmale expressing PIgc-35::LGC-35::GFP and Punc-47::mCherry. Arrows indicate spicules and oblique muscles. C, Male cloacal neurons express the GABA vesicular transporter gene unc-47. Nomarski (left panel) and fluorescence (middle panel) images of the lateral tail of Punc-47::GFP expressing in an ox/s 12 him-5(e1490) male. The PCC neurons strongly express the transgene, whereas weak expression can be detected in the PCB postcloacal sensilla neurons and the SPC proprioceptive neurons. $D$, An abbreviated connectome of the postcloacal sensilla neurons and the male sex muscles. Lines with arrows or bars represent chemical or electrical connections, respectively. Muscles in the male cloacal region: $A 0 B$, Anterior oblique; POB, posterior oblique; GER, gubernaculum erector; GRT, gubernaculum retractor; DSP, dorsal spicule protractor; VSP, ventral spicule protractor; ADP, anal depressor. $\boldsymbol{E}$, lgc-35 mating ability. There is no difference in cross progeny number between lgc-35(tm 1444) him-8(e1489) double mutants versus him-8(e1489) single-mutant controls for a single males performance at 1,3, and $24 \mathrm{~h}$ time points $(p>0.05, n=4$ plates/time point/genotype). There was a significant difference at the $6 \mathrm{~h}$ time point $(p=$ $0.037, n=4$ plates/time point/genotype)., , lgc-35 mating potency. There is no difference between lgc-35(tm1444) him-8(e1489) versus him-5(e1490) male mating potency measured by the percentage of males that can sire progeny over time (Fisher exact test, $n=20$ males/genotype/d). G, Spicule eversion. An everted spicule refers to spicules permanently everted from the body cavity of adult male at $48 \mathrm{~h}$. All animals are in a him-8(e 1489) background. Spicule eversion is not different in wild-type males $(5.7 \pm 2.8 \%, n=70)$ compared with $h i m-8(e 1489)$ controls $(9.83 \pm 3.8 \%, n=61, p>0.05) .19 c-35$ (tm 1444$)$ mutants $(1.58 \pm 1.5 \%, n=63)$ have significantly fewer everted spicules compared with him-8(e 1489$)$ controls $\left({ }^{*} p<0.05\right)$. unc-49(e407) mutants $(40.4 \pm 6.8 \%, n=52)$ exhibit significantly increased spicule eversion compared with him-8(e1489) controls $\left.{ }^{* * * *} p<0.0001\right)$. The enhanced spicule eversion phenotype in unc-49(e407) mutants is suppressed by loss of lgc-35 (lgc-35(tm 1444) unc-49(e407) $\left(1.22 \pm 1.1 \%, n=82 ;{ }^{* * * *} p<0.0001\right)$. Suppression of spicule eversion in $\operatorname{lgc}-35(\mathrm{tm} 1444)$ unc-49(e407) mutants was reversed by microinjection of an LGC-35::GFP-rescuing construct (34.1 $\pm 7.23 \%, n=$ 44). One-way ANOVA with Tukey post hoc was used for multiple comparisons. n.S., Not significant. Data are mean \pm SEM. Scale bar, $10 \mu \mathrm{m}$. 
contain the critical negative charge at the $-1^{\prime}$ position. Instead, the closest residue is a neutral serine. One model is that phosphorylation of the $-3^{\prime}$ serine may provide the negative electrostatic environment that favors cation selectivity. Interestingly, the analogous residue in EXP-1 is a negatively charged glutamate residue, suggesting that charge in this position may play an important role in conferring cation selectivity. Alternatively, the ETS motif in LGC-35 may substitute for the PAR motif present in anionic channels and provide the electrostatics for cation permeability (Jones and Sattelle, 2008; Wotring and Weiss, 2008). Together, these observations suggest that LGC-35 evolved a novel strategy for cation permeability and that the molecular and electrostatic requirements for ion selectivity may be more flexible than previously appreciated.

\section{Enteric muscle contraction}

The enteric muscles are comprised of two intestinal muscles, the sphincter and anal depressor muscle; contraction of these muscles during the defecation cycle is mediated by the GABA motor neurons AVL and DVB (White et al., 1986; McIntire et al., 1993b) (Fig. 4C). Contraction of the intestinal and anal depressor muscles is mediated by the GABA-gated cation channel EXP-1 (Thomas, 1990; McIntire et al., 1993a; Beg and Jorgensen, 2003), and the sphincter muscle contraction is mediated by LGC-35 (current study; Fig. 4C). Contraction of these muscles is ordered from anterior to posterior: (1) the intestinal muscles contract and fill the rectum with gut contents (EXP-1-mediated); (2) the sphincter muscle contracts to seal the intestine and prevent reflux (LGC-35-mediated); and (3) the anal depressor lifts the roof of the anus (EXP-1-mediated) and turgor pressure collapses the rectum driving expulsion. Because the enteric muscles are connected by gap junctions, the presence of either one of these receptors is able to stimulate some muscle contractions. Only by eliminating both receptors are contractions eliminated, fully recapitulating the defecation phenotype of mutants lacking the biosynthetic enzyme for GABA (Jin et al., 1999).

Why are two GABA-gated cation channels (LGC-35 and EXP-1) needed for enteric muscle contraction? One possibility is that differences in receptor localization and desensitization coordinate the proper timing and length of each muscle contraction. EXP-1 is less sensitive to GABA $(\sim 27 \mu \mathrm{M})$, rapidly desensitizing and highly clustered at the AVL/DVB neuromuscular junction (Beg and Jorgensen, 2003), whereas LGC-35 is more sensitive to GABA $(\sim 15 \mu \mathrm{M})$, desensitizes slowly, and is diffusely expressed in the sphincter muscle, with no apparent clustering or enrichment at the synapse (Fig. 4C). These properties suggest that synaptic signaling from AVL and DVB motor neurons rapidly activates the intestinal muscles via EXP-1, whereas spillover transmission onto LGC-35 causes a prolonged sphincter muscle contraction safeguarding against reflux of the expellant during opening of the anus. In addition, the inhibitory GABA receptor isoform UNC-49B is expressed in the sphincter muscle but not in the anal depressor or intestinal muscles (Bamber et al., 1999). Sphincter relaxation is important for defecation in adult males, but there is not an apparent role in hermaphrodites (Reiner and Thomas, 1995).

\section{Spicule eversion and mating}

Lack of inhibitory inputs into male specific muscles mediated by the GABA-gated chloride channel UNC-49 causes the spicules to extend, become permanently everted, and hang from the cloaca. This phenotype is likely due to an excess of excitatory inputs into these muscles caused by loss of inhibitory input. Because loss of the excitatory GABA receptor LGC-35 suppresses this phenotype, it is likely that GABA acts to stimulate the spicule protractor muscle. Surprisingly, loss of LGC-35 did not result in a significant defect in male mating ability or potency in $\operatorname{lgc}$ - 35 mutants. It is possible that exp-1 and $\operatorname{lgc}$ - 35 provide overlapping functions, but the contribution from $\exp -1$ is essential because it is required for male mating (E. Jorgensen, unpublished data). Alternatively, lgc-35 GABA signaling might be redundant with acetylcholine signaling. Surprisingly the PCC, PCB, and SPC neurons express vesicular transporters for both GABA and acetylcholine, and the target oblique muscles express both the GABA receptor LGC-35 and acetylcholine receptor subunits (UNC-38, UNC-63, UNC29, LEV-1, ACR-16, and ACR-18) (Liu et al., 2011). The release of two transmitters violates Dale's principle of "one neuron: one transmitter" (Eccles et al., 1954), but there are now several examples of transmitter corelease (Hnasko and Edwards, 2012) and even an example of GABA and acetylcholine corelease (Lee et al., 2010).

\section{GABA acts in spillover neurotransmission on locomotory motor neurons}

In C. elegans, GABA receptors mostly act at neuromuscular junctions (Schuske et al., 2004). Here, we find that the excitatory GABA receptor LGC-35 is expressed in the sphincter muscle and also in the acetylcholine motor neurons. The loss of excitatory GABA input into the acetylcholine motor neurons leads to decreased acetylcholine output, observed as an aldicarb-resistant phenotype in $\lg c$ - 35 mutants. These excitatory GABA inputs are both direct and indirect.

There are some direct synaptic contacts between the ventral VD GABA motor neurons and the ventral acetylcholine motor neurons that are observed in the wiring diagram (Chen et al., 2006). However, they are a minor component of the output of these motor neurons; for example, the VD3 GABA motor neuron forms 23 synapses to ventral body muscle but only 2 synapses each to VA3 and VB2 (Chen et al., 2006). Moreover, the DD neurons, for the most part, do not have similar inputs into the DA and DB motor neurons. This connectivity appears counterproductive: GABA release will simultaneously inhibit muscle contraction directly via UNC-49 and indirectly drive muscle contraction by stimulating acetylcholine release. However, it is likely that these direct inputs serve to initiate a rebound of the acetylcholine motor neurons to reverse the flexure during locomotion. Consistent with this model, $\operatorname{lgc}-35$ mutants exhibit exaggerated bending in liquid or on solid surfaces, likely due to an inability to reverse ipsilateral relaxation that leads to flexures of greater amplitude.

The dominant inputs from GABA neurons to acetylcholine neurons are not via direct inputs but rather through indirect inputs, mediated by spillover transmission. In addition to receiving direct inputs from GABA neurons, LGC-35 is largely distributed on acetylcholine axons between GABA neuromuscular junctions; in other words, LGC-35 is not juxtaposed to GABA release sites but rather is found between them. As expected for a receptor that is distant to a release site, LGC-35 exhibits increased sensitivity to GABA compared with the inhibitory GABA receptor on muscles juxtaposed to the release site (LGC-35 EC E0 $_{50} 15$ $\mu \mathrm{M}$; UNC-49 $\mathrm{EC}_{50}=44 \mu \mathrm{M}$ ) (Bamber et al., 1999). In addition, unlike other GABA neurons in the worm, the ventral cord GABA motor neurons do not express the GABA transporter SNF-11 (Mullen et al., 2006), nor do they show GABA uptake activity (McIntire et al., 1993a). In the absence of rapid clearance, GABA 
spillover along the motor neurons will activate the acetylcholine motor neurons.

Spillover transmission is not unique to nematodes. There are examples in vertebrate circuits where neurotransmission has indirect components (Nishiyama and Linden, 2007). In these circuits, spillover transmission may function to modify direct synaptic signaling. For example, climbing fibers in the mouse cerebellum make thousands of direct excitatory synaptic contacts with their primary target Purkinje cells. These same climbing fibers also communicate with inhibitory cerebellar basket and stellate interneurons exclusively by spillover transmission (Szapiro and Barbour, 2007). Additionally, inhibitory Golgi-granule cell communication in the cerebellum is predominantly mediated by spillover transmission (Rossi and Hamann, 1998). Together, these data and our findings reveal that spillover transmission adds an additional layer of complexity to neuronal circuits and underscores that simply mapping synaptic connectivity cannot describe how behavioral output is encoded at the circuit level.

\section{References}

Amin J, Weiss DS (1993) GABAA receptor needs two homologous domains of the beta-subunit for activation by GABA but not by pentobarbital. Nature 366:565-569. CrossRef Medline

Bamber BA, Beg AA, Twyman RE, Jorgensen EM (1999) The Caenorhabditis elegans unc-49 locus encodes multiple subunits of a heteromultimeric GABA receptor. J Neurosci 19:5348-5359. Medline

Beg AA, Jorgensen EM (2003) EXP-1 is an excitatory GABA-gated cation channel. Nat Neurosci 6:1145-1152. CrossRef Medline

Beg AA, Ernstrom GG, Nix P, Davis MW, Jorgensen EM (2008) Protons act as a transmitter for muscle contraction in C. elegans. Cell 132:149-160. CrossRef Medline

Boileau AJ, Evers AR, Davis AF, Czajkowski C (1999) Mapping the agonist binding site of the GABAA receptor: evidence for a beta-strand. J Neurosci 19:4847-4854. Medline

Boileau AJ, Newell JG, Czajkowski C (2002) GABA(A) receptor beta 2 Tyr97 and Leu99 line the GABA-binding site. Insights into mechanisms of agonist and antagonist actions. J Biol Chem 277:2931-2937. CrossRef Medline

Chen BL, Hall DH, Chklovskii DB (2006) Wiring optimization can relate neuronal structure and function. Proc Natl Acad Sci U S A 103:47234728. CrossRef Medline

Corringer PJ, Bertrand S, Galzi JL, Devillers-Thiéry A, Changeux JP, Bertrand D (1999) Mutational analysis of the charge selectivity filter of the alpha7 nicotinic acetylcholine receptor. Neuron 22:831-843. CrossRef Medline

Croll NA (1975) Behavioural analysis of nematode movement. Adv Parasitol 13:71-122. CrossRef Medline

Eccles JC, Fatt P, Koketsu K (1954) Cholinergic and inhibitory synapses in a pathway from motor-axon collaterals to motoneurones. J Physiol 126: 524-562. CrossRef Medline

Frøkjær-Jensen C, Davis MW, Hollopeter G, Taylor J, Harris TW, Nix P, Lofgren R, Prestgard-Duke M, Bastiani M, Moerman DG, Jorgensen EM (2010) Targeted gene deletions in C. elegans using transposon excision. Nat Methods 7:451-453. CrossRef Medline

Galzi JL, Devillers-Thiéry A, Hussy N, Bertrand S, Changeux JP, Bertrand D (1992) Mutations in the channel domain of a neuronal nicotinic receptor convert ion selectivity from cationic to anionic. Nature 359:500-505. CrossRef Medline

Garcia LR, Sternberg PW (2003) Caenorhabditis elegans UNC-103 ERG-like potassium channel regulates contractile behaviors of sex muscles in males before and during mating. J Neurosci 23:2696-2705. Medline

Garcia LR, Mehta P, Sternberg PW (2001) Regulation of distinct muscle behaviors controls the C. elegans male's copulatory spicules during mating. Cell 107:777-788. CrossRef Medline

Gunthorpe MJ, Lummis SC (2001) Conversion of the ion selectivity of the 5-HT(3a) receptor from cationic to anionic reveals a conserved feature of the ligand-gated ion channel superfamily. J Biol Chem 276:10977-10983. CrossRef Medline

Hnasko TS, Edwards RH (2012) Neurotransmitter corelease: mechanism and physiological role. Annu Rev Physiol 74:225-243. CrossRef Medline
Hodgkin J (1983) Male phenotypes and mating efficiency in Caenorhabditis elegans. Genetics 103:43-64. Medline

Imoto K, Busch C, Sakmann B, Mishina M, Konno T, Nakai J, Bujo H, Mori Y, Fukuda K, Numa S (1988) Rings of negatively charged amino acids determine the acetylcholine receptor channel conductance. Nature 335: 645-648. CrossRef Medline

Jarrell TA, Wang Y, Bloniarz AE, Brittin CA, Xu M, Thomson JN, Albertson DG, Hall DH, Emmons SW (2012) The connectome of a decisionmaking neural network. Science 337:437-444. CrossRef Medline

Jensen ML, Timmermann DB, Johansen TH, Schousboe A, Varming T, Ahring PK (2002) The beta subunit determines the ion selectivity of the GABAA receptor. J Biol Chem 277:41438-41447. CrossRef Medline

Jensen ML, Schousboe A, Ahring PK (2005a) Charge selectivity of the Cysloop family of ligand-gated ion channels. J Neurochem 92:217-225. CrossRef Medline

Jensen ML, Pedersen LN, Timmermann DB, Schousboe A, Ahring PK (2005b) Mutational studies using a cation-conducting GABAA receptor reveal the selectivity determinants of the Cys-loop family of ligand-gated ion channels. J Neurochem 92:962-972. CrossRef Medline

Jin Y, Jorgensen E, Hartwieg E, Horvitz HR (1999) The Caenorhabditis elegans gene unc- 25 encodes glutamic acid decarboxylase and is required for synaptic transmission but not synaptic development. J Neurosci 19: 539-548. Medline

Jones AK, Sattelle DB (2008) The cys-loop ligand-gated ion channel gene superfamily of the nematode, Caenorhabditis elegans. Invert Neurosci 8:41-47. CrossRef Medline

Jospin M, Qi YB, Stawicki TM, Boulin T, Schuske KR, Horvitz HR, Bessereau JL, Jorgensen EM, Jin Y (2009) A neuronal acetylcholine receptor regulates the balance of muscle excitation and inhibition in Caenorhabditis elegans. PLoS Biol 7:e1000265. CrossRef Medline

Kamath RS, Fraser AG, Dong Y, Poulin G, Durbin R, Gotta M, Kanapin A, Le Bot N, Moreno S, Sohrmann M, Welchman DP, Zipperlen P, Ahringer J (2003) Systematic functional analysis of the Caenorhabditis elegans genome using RNAi. Nature 421:231-237. CrossRef Medline

Keramidas A, Moorhouse AJ, French CR, Schofield PR, Barry PH (2000) M2 pore mutations convert the glycine receptor channel from being anion- to cation-selective. Biophys J 79:247-259. CrossRef Medline

Keramidas A, Moorhouse AJ, Pierce KD, Schofield PR, Barry PH (2002) Cation-selective mutations in the M2 domain of the inhibitory glycine receptor channel reveal determinants of ion-charge selectivity. J Gen Physiol 119:393-410. CrossRef Medline

Lee S, Kim K, Zhou ZJ (2010) Role of ACh-GABA cotransmission in detecting image motion and motion direction. Neuron 68:1159-1172. CrossRef Medline

Liu DW, Thomas JH (1994) Regulation of a periodic motor program in C. elegans. J Neurosci 14:1953-1962. Medline

Liu KS, Sternberg PW (1995) Sensory regulation of male mating behavior in Caenorhabditis elegans. Neuron 14:79-89. CrossRef Medline

Liu Y, LeBeouf B, Guo X, Correa PA, Gualberto DG, Lints R, Garcia LR (2011) A cholinergic-regulated circuit coordinates the maintenance and bi-stable states of a sensory-motor behavior during Caenorhabditis elegans male copulation. PLoS Genet 7:e1001326. CrossRef Medline

Mahoney TR, Luo S, Nonet ML (2006) Analysis of synaptic transmission in Caenorhabditis elegans using an aldicarb-sensitivity assay. Nat Protoc 1:1772-1777. CrossRef Medline

Maruyama IN, Rakow TL, Maruyama HI (1995) cRACE: a simple method for identification of the $5^{\prime}$ end of mRNAs. Nucleic Acids Res 23:37963797. CrossRef Medline

McIntire SL, Jorgensen E, Horvitz HR (1993a) Genes required for GABA function in Caenorhabditis elegans. Nature 364:334-337. CrossRef Medline

McIntire SL, Jorgensen E, Kaplan J, Horvitz HR (1993b) The GABAergic nervous system of Caenorhabditis elegans. Nature 364:337-341. CrossRef Medline

Mello CC, Kramer JM, Stinchcomb D, Ambros V (1991) Efficient gene transfer in C. elegans: extrachromosomal maintenance and integration of transforming sequences. EMBO J 10:3959-3970. Medline

Miller KG, Alfonso A, Nguyen M, Crowell JA, Johnson CD, Rand JB (1996) A genetic selection for Caenorhabditis elegans synaptic transmission mutants. Proc Natl Acad Sci U S A 93:12593-12598. CrossRef Medline

Mullen GP, Mathews EA, Saxena P, Fields SD, McManus JR, Moulder G, Barstead RJ, Quick MW, Rand JB (2006) The Caenorhabditis elegans 
snf-11 gene encodes a sodium-dependent GABA transporter required for clearance of synaptic GABA. Mol Biol Cell 17:3021-3030. CrossRef Medline

Nishiyama H, Linden DJ (2007) Pure spillover transmission between neurons. Nat Neurosci 10:675-677. CrossRef Medline

Peden AS, Mac P, Fei YJ, Castro C, Jiang G, Murfitt KJ, Miska EA, Griffin JL, Ganapathy V, Jorgensen EM (2013) Betaine acts on a ligand-gated ion channel in the nervous system of the nematode C. elegans. Nat Neurosci 16:1794-1801. CrossRef Medline

Pirri JK, McPherson AD, DonnellyJL, Francis MM, Alkema MJ (2009) A tyraminegated chloride channel coordinates distinct motor programs of a Caenorhabditis elegans escape response. Neuron 62:526-538. CrossRef Medline

Putrenko I, Zakikhani M, Dent JA (2005) A family of acetylcholine-gated chloride channel subunits in Caenorhabditis elegans. J Biol Chem 280: 6392-6398. CrossRef Medline

Ranganathan R, Cannon SC, Horvitz HR (2000) MOD-1 is a serotoningated chloride channel that modulates locomotory behaviour in C. elegans. Nature 408:470-475. CrossRef Medline

Reiner DJ, Thomas JH (1995) Reversal of a muscle response to GABA during C. elegans male development. J Neurosci 15:6094-6102. Medline

Ringstad N, Abe N, Horvitz HR (2009) Ligand-gated chloride channels are receptors for biogenic amines in C. elegans. Science 325:96-100. CrossRef Medline

Rossi DJ, Hamann M (1998) Spillover-mediated transmission at inhibitory synapses promoted by high affinity alpha6 subunit GABA(A) receptors and glomerular geometry. Neuron 20:783-795. CrossRef Medline

Schuske K, Beg AA, Jorgensen EM (2004) The GABA nervous system in C. elegans. Trends Neurosci 27:407-414. CrossRef Medline

Sigel E, Baur R, Kellenberger S, Malherbe P (1992) Point mutations affecting antagonist affinity and agonist dependent gating of GABAA receptor channels. EMBO J 11:2017-2023. Medline

Szapiro G, Barbour B (2007) Multiple climbing fibers signal to molecular layer interneurons exclusively via glutamate spillover. Nat Neurosci 10: 735-742. CrossRef Medline
Thomas JH (1990) Genetic analysis of defecation in Caenorhabditis elegans. Genetics 124:855-872. Medline

Thompson AJ, Lester HA, Lummis SC (2010) The structural basis of function in Cys-loop receptors. Q Rev Biophys 43:449-499. CrossRef Medline

Wagner DA, Czajkowski C (2001) Structure and dynamics of the GABA binding pocket: a narrowing cleft that constricts during activation. J Neurosci 21:67-74. Medline

Wang SJ, Wang ZW (2013) Track-a-worm, an open-source system for quantitative assessment of $C$. elegans locomotory and bending behavior. PLoS One 8:e69653. CrossRef Medline

Weber W (1999) Ion currents of Xenopus laevis oocytes: state of the art. Biochim Biophys Acta 1421:213-233. CrossRef Medline

Westh-Hansen SE, Rasmussen PB, Hastrup S, Nabekura J, Noguchi K, Akaike N, Witt MR, Nielsen M (1997) Decreased agonist sensitivity of human $\mathrm{GABA}(\mathrm{A})$ receptors by an amino acid variant, isoleucine to valine, in the alpha1 subunit. Eur J Pharmacol 329:253-257. CrossRef Medline

Westh-Hansen SE, Witt MR, Dekermendjian K, Liljefors T, Rasmussen PB, Nielsen M (1999) Arginine residue 120 of the human GABAA receptor alpha 1, subunit is essential for GABA binding and chloride ion current gating. Neuroreport 10:2417-2421. CrossRef Medline

White JG, Southgate E, Thomson JN, Brenner S (1986) The structure of the nervous system of the nematode Caenorhabditis elegans. Philos Trans R Soc Lond B Biol Sci 314:1-340. CrossRef Medline

Wotring VE, Weiss DS (2008) Charge scan reveals an extended region at the intracellular end of the GABA receptor pore that can influence ion selectivity. J Gen Physiol 131:87-97. CrossRef Medline

Wotring VE, Miller TS, Weiss DS (2003) Mutations at the GABA receptor selectivity filter: a possible role for effective charges. J Physiol 548:527540. CrossRef Medline

Yassin L, Gillo B, Kahan T, Halevi S, Eshel M, Treinin M (2001) Characterization of the deg-3/des-2 receptor: a nicotinic acetylcholine receptor that mutates to cause neuronal degeneration. Mol Cell Neurosci 17:589-599. CrossRef Medline 